University of Louisville

ThinkIR: The University of Louisville's Institutional Repository

$12-2012$

\title{
Effect of viewing conditions on the detection of proximal dental caries in intraoral digital images with and without computer- assisted diagnosis.
}

Lauren Christine Szechy 1989-

University of Louisville

Follow this and additional works at: https://ir.library.louisville.edu/etd

\section{Recommended Citation}

Szechy, Lauren Christine 1989-, "Effect of viewing conditions on the detection of proximal dental caries in intraoral digital images with and without computer-assisted diagnosis." (2012). Electronic Theses and Dissertations. Paper 1413.

https://doi.org/10.18297/etd/1413

This Master's Thesis is brought to you for free and open access by ThinkIR: The University of Louisville's Institutional Repository. It has been accepted for inclusion in Electronic Theses and Dissertations by an authorized administrator of ThinkIR: The University of Louisville's Institutional Repository. This title appears here courtesy of the author, who has retained all other copyrights. For more information, please contact thinkir@louisville.edu. 


\title{
EFFECT OF VIEWING CONDITIONS ON THE DETECTION OF PROXIMAL DENTAL CARIES IN INTRAORAL DIGITAL IMAGES WITH AND WITHOUT COMPUTER-ASSISTED DIAGNOSIS
}

\author{
By \\ Lauren Christine Szechy \\ B.S., University of Dayton, 2011

\begin{abstract}
A Thesis
Submitted to the Faculty of the University of Louisville School of Dentistry In Partial Fulfillment of the Requirements

For the Degree of
\end{abstract} \\ Master of Oral Biology \\ University of Louisville \\ Louisville, Kentucky
}

December 2012 


\title{
EFFECT OF VIEWING CONDITIONS ON THE DETECTION OF PROXIMAL DENTAL CARIES IN INTRAORAL DIGITAL IMAGES WITH AND WITHOUT COMPUTER-ASSISTED DIAGNOSIS
}

\author{
By \\ Lauren Christine Szechy \\ B.S., University of Dayton, 2011
}

A Thesis Approved on

December $7^{\text {th }}, 2012$

By the following Thesis Committee:

Dr. William C. Scarfe, Thesis Co-Director

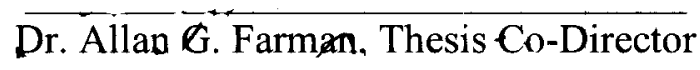

Dr. Anibal Silveira, Committee Member

Dr. Jamies P. Scheetz, Committee Member 


\section{ACKNOWLEDGEMENTS}

I would like to recognize and thank the following individuals:

Dr. William C Scarfe, Thesis Co-Director, for giving me the opportunity to conduct this research, for his many hours of help and support of this endeavor, and for his interest in this project.

Dr. Allan G Farman, Thesis Co-Director, for also giving me the opportunity to conduct this research, for his excitement in the study, and for his insightful guidance and encouragement throughout the project.

Dr. James P Scheetz, Thesis Committee Member, for his helpful insight regarding the data management and statistical analysis.

Dr. David Gakenheimer for donating materials and many hours of help, as well as his support and guidance throughout this research.

Dr. Timothy Daugherty for his help, support, and interest in this research and in recruitment of the observers.

Dr. Brad Dykstra for donating materials and carefully documenting clinical evidence of true positive findings. 


\begin{abstract}
EFFECT OF VIEWING CONDITIONS ON THE DETECTION OF PROXIMAL DENTAL CARIES IN INTRAORAL DIGITAL IMAGES WITH AND WITHOUT COMPUTER-ASSISTED DIAGNOSIS
\end{abstract}

\author{
Lauren C. Szechy \\ December 7, 2012
}

Background: Dental caries is the most common childhood ailment and one of the most prevalent chronic diseases of people worldwide. Approximately $91 \%$ of dentate adults 20 years or older have experienced dental caries. Carious lesions on proximal surfaces are particularly difficult to detect clinically, which is why intraoral radiography has become a supplemental method used to aid diagnosis. It was hypothesized that the accuracy of detection of proximal caries with the unaided eye would be reduced in sub-optimal viewing conditions; furthermore, the use of computer-assisted diagnostic software (Logicon Caries Detector) would improve the overall accuracy of observers. Methods: Eighteen radiographs with 214 surfaces were evaluated by 12 observers (general dental practitioners acting as attending faculty from University of Louisville School of Dentistry). Each observer viewed the designated surfaces in each of the viewing 
conditions, both with and without LCD software. The viewing conditions included: 1) brightly lit room 2) dark room, and 3) brightly lit room with plastic infection control bags on the monitors. The sensitivity and specificity of each evaluator were calculated and compared for each of the conditions using ANOVA at the significance level of $p \leq 0.05$. Results: Sensitivity was significantly worse in the protective barrier condition than in the dark and bright rooms. With sharpening alone, diagnostic ability increased up to $8.59 \%$, and LCD increased accuracy up to $17.22 \%$. The data for specificity was slightly scattered due to a small sample size of caries-free surfaces. Conclusions: In such conditions when poor lighting and barriers can take away from diagnostic ability, computer assisted software can be a useful tool to help dentists perform as well, or better than in optimal conditions. 


\section{TABLE OF CONTENTS}

PAGE

ACKNOWLEDGEMENTS

ABSTRACT iv

LIST OF TABLES vii

LIST OF FIGURES viii

CHAPTER I: INTRODUCTION 1

CHAPTER II: REVIEW OF THE LITERATURE

CHAPTER III: MATERIALS AND METHODS 12

$\begin{array}{ll}\text { CHAPTER IV: RESULTS } & 24\end{array}$

CHAPTER V: DISCUSSION 29

$\begin{array}{ll}\text { CHAPTER VI: CONCLUSION } & 30\end{array}$

REFERENCES

$\begin{array}{ll}\text { APPENDICES } & 36\end{array}$

CURRICULUM VITAE 


\section{LIST OF TABLES}

TABLE

1 Statistical Ratings

2 Sensitivity - True Positive Rate

3 Specificity - True Negative Rate

4 Accuracy
PAGE

23

27

27

28 


\section{LIST OF FIGURES}

FIGURE

PAGE

1 Logicon Caries Detector V Tool 10

2 LCD Diagnostic Outputs $\quad 10-11$

3 Radiographic Classification of Caries $\quad 15$

4 Observer Answer Sheet 16

5 Observer Answer Sheet with Restorations $\quad 17$

6 Dark Room Viewing Condition 18

7 Clinical Operatory, Bright Room Viewing Condition 19

8 Protective Barrier Viewing Condition $\quad 19$

9 TG10-QC Calibration Pattern 20

10 Examples of Sub-Conditions $\quad 21$

11 Clinical Confirmation of Caries 25-26 


\section{CHAPTER I INTRODUCTION}

\section{Background and Significance}

Dental caries is the localized destruction of susceptible dental hard tissues by acidic by-products from bacterial fermentation of dietary carbohydrates. It is the most common childhood ailment and one of the most prevalent chronic diseases of people worldwide. Individuals are susceptible to the disease throughout their lifetime. Approximately $91 \%$ of dentate adults 20 years or older have experienced dental caries. ${ }^{1}$ If left untreated, dental caries will progress to include the dental pulp, cause excruciating pain and ultimately require tooth removal. Dental carious lesions on contacting proximal surfaces of adjacent teeth are particularly difficult to detect in clinical dental practice either visually or with a dental explorer. Intraoral radiography using the bitewing technique is generally the method used to supplement the diagnosis of proximal dental caries. Dental radiography has an overall sensitivity of $50 \%$ and a specificity of $87 \%$ in

detecting interproximal dental caries. ${ }^{2}$ Thus, using conventional clinical and radiographic methods, a dentist can detect only about half the dental carious lesions present and, could potentially misclassify sizeable numbers of sound surfaces as decayed. Such decisions could lead to providing treatment when none is warranted - over-treatment. Furthermore, visually diagnosing radiographic images for proximal caries is difficult because of 
variations in radiographs due to exposure level, tooth structure and tooth shape, and because the eye tends to smooth out shades of gray. ${ }^{3}$ Finally, just detecting dental caries is not sufficient to assess need for restorative treatment. Such a decision is predicted by an accurate determination of the degree of penetration of the process through the tooth enamel and into dentin.

The most important variables when interpreting digital dental radiographic images are the monitor, ${ }^{4}$ the viewing conditions, ${ }^{4-6}$ and the observer. ${ }^{7}$ The use of poor quality monitors and viewing conditions have a negative impact on the ability to detect small density differences displayed on dental radiographic images. However, the experience of observers and their ability to use software to adjust brightness and contrast of images are as important, or perhaps, even more important, as these technical considerations.

Logicon Caries Detector (LCD), a patented, FDA conformant computer diagnostic tool is an example of available computer assisted diagnostic software which has been shown to improve radiographic detection rates of proximal surface caries from $30 \%$ up to $69 \%{ }^{6}$ Logicon software allows dentists to inspect potential lesions on proximal surfaces. The software then determines whether there is a lesion and if it penetrates deep enough to deserve treatment. ${ }^{8}$ The software does this by means of analyzing density changes (shades of gray) in the tooth.

\section{Objectives}

The main purpose of this study is to determine if the overall accuracy of multiple observers in the detection of proximal dental caries requiring dental restoration with the unaided eye in sub-optimal viewing conditions is reduced. Furthermore, because 
computer assisted diagnostic software is independent of monitor and, to a certain extent, observer, the use of such a program in variable viewing conditions is expected to improve the overall accuracy of observers in the detection of proximal dental caries and the decision threshold of treat/no treat. The understanding of the influence of optimal viewing conditions and use of computer assisted software on the diagnosis of treatable proximal dental caries should provide dentists with greater accuracy in this clinically important task.

\section{Specific Aims}

The aims of this investigation are to compare the effect of two dependent variables on the unaided visual detection of proximal dental caries requiring restoration on digital intraoral radiographic images by multiple observers:

1. Different viewing conditions

a. Optimal conditions - A darkened room with no ambient lighting. (Dark Room)

b. Clinical operatory - A brightly lit dental operatory with overhead fluorescent lighting (Bright Room)

c. Clinical operatory with infection control barriers - A brightly lit dental operatory with overhead fluorescent lighting with a plastic infection control barrier over the monitor.

2. Computer-assisted diagnostic software program (Logicon Caries Detector, Carestream KODAK Dental, Augusta, GA, USA). 


\section{CHAPTER II}

\section{REVIEW OF THE LITERATURE}

\section{Primary Diagnosis of Proximal Caries}

Visual and clinical inspection is the primary method used for diagnosis of proximal dental caries. This is performed using a dental explorer and dental mirror. In the majority of cases, visual identification is difficult due to the location of the caries. The mesial and distal surfaces of teeth are somewhat "hidden" to the eye, which is why secondary methods of diagnosis are used in addition to clinical inspection.

In March 2001, the National Institute of Health (NIH) published a consensus statement on the diagnosis and management of dental caries, expressing a need for advances in radiographic methods of diagnosing non-cavitated lesions and a need for clinical studies to evaluate the efficacy of new methods. The work reported in this thesis contributes to both of these needs as identified by the NIH panel of non-advocate, nonfederal experts following a number of presentations from prominent investigators in the field. ${ }^{9}$

\section{Intraoral Radiography}

Intraoral radiography using the bitewing technique is generally the method used to supplement the diagnosis of proximal dental caries. When viewing a radiograph, a 
dentist detects caries when he/she sees a small notching decrease in shade of gray (called a radiolucency) on the enamel surface, just below the proximal contact point.

Histopathologically, as the carious lesion in the enamel follows the path of the enamel rods and increases in size, it demonstrates a triangular pattern with its base towards the outer surface of the tooth and with a flattened apex towards the dentinoenamel junction. After reaching the DEJ, the carious lesion spreads along the junction and forms a second base. From this second base, the caries proceeds towards the pulp along the path of the dentinal tubules and forms another triangular radiolucency with the apex towards the pulp. Thus, proximal caries progresses to form two triangular areas with the base of the first triangle at the outer enamel surface of the tooth and the base of the second triangle at the DEJ. When the undermined enamel fractures, the entire carious lesion radiographically resembles a $U$ shape. ${ }^{10}$

There are a number of special circumstances and situations where artificial radiolucencies may appear on radiographs and can be confused with dental caries. These situations may lead the dentist to falsely predict decay where there is none. It is important for the dentist to be familiar with these instances and be able to distinguish dental caries from them, in order to avoid unnecessarily restoring sound tooth material. The most common one is cervical burnout. This is an illusion of radiolucency of a radiopaque object. Typically, this appears as a radiolucent area between the crown and the portion of the root covered by alveolar bone. This occurs because that area absorbs fewer $\mathrm{x}$-ray photons than the adjoining areas. ${ }^{10} \mathrm{~A}$ second $\mathrm{x}$-ray may be taken with different angulation or exposure in attempt to avoid cervical burnout. Other situations 
include shadows caused by pulling the lip back when taking a radiograph, shadows caused by foreign objects such as sponges or cotton rolls, shadows underneath the occlusal ridge, concave surfaces, badly overlapping teeth, and problematic tooth geometry in general.

Radiography has an overall sensitivity of $50 \%$ and a specificity of $87 \%$ in detecting interproximal dental caries. ${ }^{8}$ Thus, using conventional clinical and radiographic methods, a dentist can detect only about half the lesions present and, could misclassify sizeable numbers of sound surfaces as decayed. Furthermore, visually diagnosing radiographic images for proximal caries is difficult because of variations in radiographs due to exposure level, tooth structure and tooth shape, and because the eye tends to smooth out shades of gray. ${ }^{3}$ Finally, just detecting dental caries is not sufficient to assess need for restorative treatment. Such a decision is predicated by an accurate determination of the degree of penetration of the process through the tooth enamel and into the dentin.

The most important variables when interpreting digital dental radiographic images are the monitor, ${ }^{4}$ the viewing conditions, ${ }^{4-6}$ and the observer. ${ }^{7}$ The use of poor quality monitors and viewing conditions may have a negative impact on the ability to detect small density differences displayed on dental radiographic images. However, the experience of observers are as important, or perhaps, even more important, as these technical considerations. Digital radiography has brought new opportunities for smart software to aid dentists in diagnosis of dental caries. 
Many computer-based image viewing programs, like Kodak Dental Imaging Software (Carestream KODAK Dental, Augusta, GA, USA), DentiMax (DentiMax LLC, Mesa, AZ, USA), and MicroDicom (Simeon Antonov Stoykov, Sofia, Bulgaria), provide several features and assessment tools that can aid dentists in diagnosis. Firstly, the large size, and ability to zoom, allows the dentist to see the image with greater magnification. Adjusting brightness and contrast, sharpening the image, and/or running different filters, allows the dentist to enhance the image to better see what they are looking for. Filters simply remove some of the radiographic information, to give a clearer view of the area in question. KDIS (Kodak Dental Imaging Software) has unique automatic presets that allow the dentist to focus on the shades of gray that are relevant to the pathology they are seeking to diagnose. For example, if the dentist clicks the periodontal icon, it will focus on the shades of gray in the spectrum that highlight the periodontal area of the tooth, including calculus on the teeth and at the soft-tissue level. The Endo icon highlights the lamina dura, the shades of the apex of the tooth, and the surrounding bone. Finally, the DEJ icon highlights the shades of gray at the DEJ interface and can be helpful in diagnosing caries. This ability to enhance and segment the gray scales makes it easier to identify and diagnose subtle changes that are often missed on other digital systems. ${ }^{5}$

\section{Logicon Caries Detector}

Logicon Caries Detector (Carestream KODAK Dental, Augusta, GA, USA), a patented, FDA approved computer diagnostic tool is an example of available computerassisted diagnostic software, which has been shown to improve radiographic detection 
rates of proximal surface caries from $30 \%$ up to $69 \%{ }^{6}$ Logicon software allows dentists to inspect potential lesions on proximal surfaces of digital bitewing images. The software then identifies variations in enamel gray-scale homogeneity, based on a database and determines the possibility of the presence of a lesion and if it penetrates deep enough to deserve treatment. ${ }^{8}$ The software does this by means of analyzing density changes (shades of gray) in tooth. A typical bitewing radiograph contains 4,096 shades of gray, most computer monitors can display 256 shades of gray. A human observer is able to perceive between 700 and 900 different shades of gray over the entire luminance range

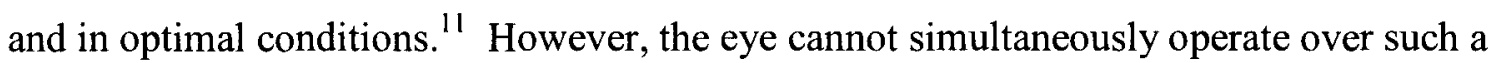
range of intensity levels and therefore operates by changing the overall sensitivity in a process called brightness adaption. At a given sensitivity, the eye can simultaneously discriminate only a relatively small number of intensity levels. For a given condition, the sensitivity of the visual system is called the brightness adaption level. The visual contrast response under fixed adaptation conditions is worse in the bright and dark areas of an image. This means that the brighter and darker image parts, and therefore subtle luminance differences, will be more difficult to see.

Logicon Caries Detector analyzes these shades of gray that cannot be seen by the human eye, therefore improving diagnostic ability. This software is the first FDA approved tool able to trace the caries from the surface through the enamel and into the dentin, and to produce probabilities that enamel and dentin lesions are present based on a comparison with a database of known caries. ${ }^{3}$

After the dentist designates the region of interest on either the distal or mesial surface of a tooth, he/she uses the V-tool to select that region (Fig 1). The program then 
runs automatically and produces three diagnostic aids (Fig 2). First, the software finds the outer edge of the tooth and the dentinoenamel junction (DEJ). Next, the program analyzes the density variation along contours paralleling the tooth surface and the DEJ. Logicon separates the region of interest into ten equally spaced contours, and looks for correlations in density dips that could be related to caries disease. If such a pattern is present, the program highlights it and outlines the edges of the density dips in red. Finally, the probability of a lesion being present is calculated based on a database of known dental caries cases. A decision threshold line, based on a fifteen percent falsepositive rate, is shown with the lesion probability bar graph. If the probability bar for a dentinal lesion is well above this decision threshold, the dentist is advised to consider restorative treatment of the tooth. On the other hand, if the probability bar is near or below the decision threshold, the dentist is advised to wait and re-evaluate the case at a later date. When the probability bar is above the decision threshold for an enamel lesion, it is based more on the dentist's judgment than on the software's output. This is because an enamel lesion alone may not progress to a severe state, or may even recalcify. ${ }^{3}$ In a 2002 study by David Gakenheimer, LCD was proven to help dentists find 20 percent more cases of caries penetrating into the dentin without causing them to misdiagnose additional healthy teeth. ${ }^{3}$ 


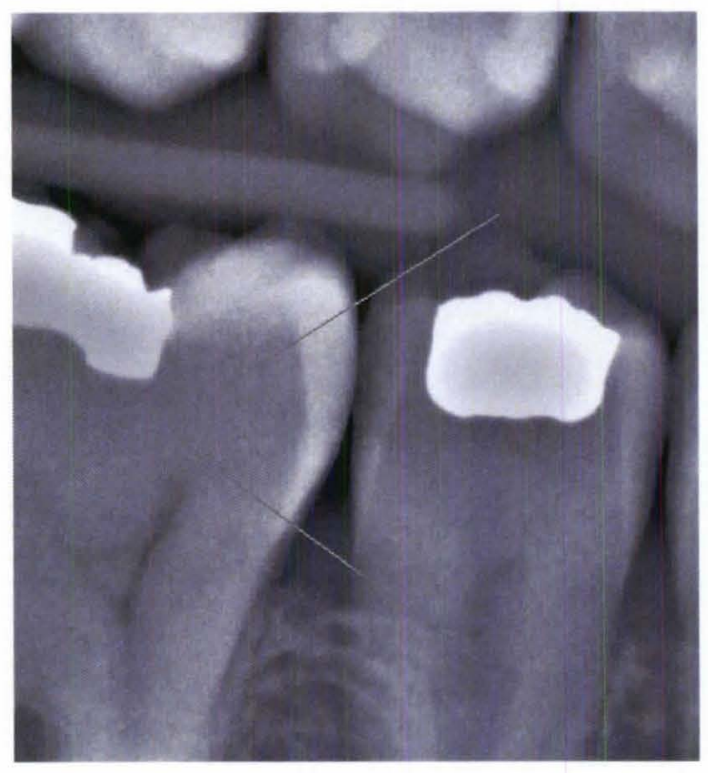

Figure 1. Cropped, enhanced bitewing image showing the localization of the $\mathrm{V}$ tool to select the proximal region on $30 \mathrm{M}$.

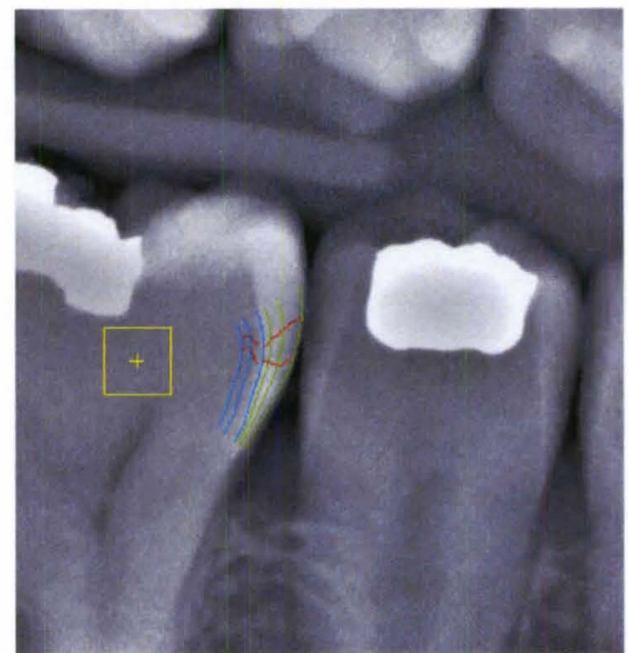

a. Radiolucency Outline

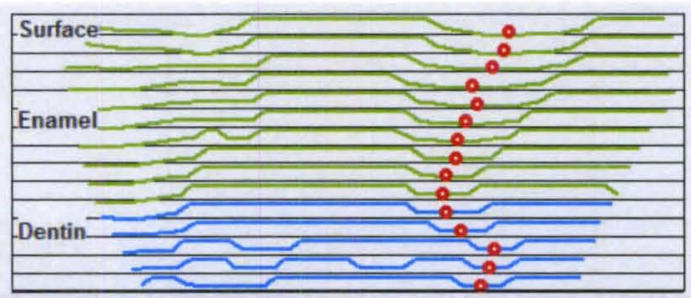

b. Tooth Density

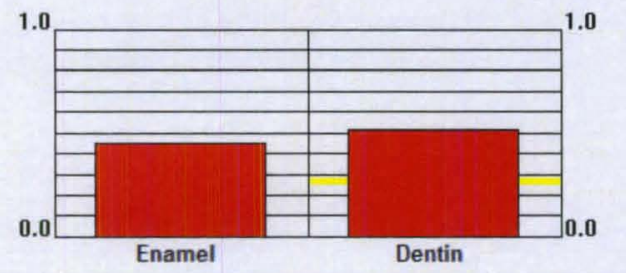

c. Lesion Probability 
Figure 2. Cropped image output from the LCD software. a) The first diagnostic output from LCD. Tooth image shows selected analysis contours and radiolucency site is outlined in red. The green lines represent the regions in the enamel, and the blue lines represent the regions in the dentin. The dentinoenamel junction (DEJ) is represented by the first blue line. b) The second diagnostic output from LCD. Tooth density change throughout the enamel and into the dentin. The radiolucency center is highlighted with red dots. c) The third diagnostic output from LCD. Lesion probability with the decision threshold (yellow line) for 15 percent false-positive results.

In January 2002, an International Consensus Workshop on Caries Clinical Trials (ICW-CCT) was held in Scotland; it included a presentation on modern concepts of caries management. Seven linked steps were proposed to facilitate caries management clinically: 1) caries detection, 2) lesion measurement, 3) lesion monitoring by repeated measures, 4) caries activity measures, 5) diagnosis, prognosis, and clinical decision-making, 6) interventions/treatments, and 7) outcome of caries control/management. The computer assisted diagnosis program described in this thesis contributes to steps $1-3$, and the results from those steps provide important input to steps 4-7. 


\section{CHAPTER III \\ MATERIALS AND METHODS}

\section{Hypothesis}

It was hypothesized that the overall accuracy of multiple observers in the detection of proximal dental caries requiring restoration with the unaided eye is reduced in suboptimal viewing conditions. Furthermore, it was hypothesized that the use of a computer assisted diagnostic software program in each viewing condition would improve the overall accuracy of observers in the detection of proximal dental caries and the decision threshold of treat/no treat.

\section{Institutional Review Board}

This study was submitted for IRB approval since it involved a retrospective chart audit. All images were de-identified and coded. Each observer also was invited to participate and signed a consent form before participating in this study (See Appendix A). IRB approval was granted on April 2, 2012 (Approval number 11.0630).

\section{Subject Selection}

The digital bitewing images of eighteen patients attending the private practice of Dr. Bradley A. Dykstra, DDS (BAD) were available for use. Images were taken using 
KODAK RVG 6100 System (Carestream KODAK Dental, Augusta, GA, USA). BAD has had the LCD for a number of years and is familiar with its operation and utility in helping to determine whether caries is present on a surface, how deep the caries extends, and whether the surface needs to be restored, treated noninvasively, or merely monitored. Images were taken on patients during routine visits where clinical examination and use of LCD have been part of BAD's protocol for years. After examination and radiographic evaluation, BAD developed a treatment plan to restore those surfaces where he diagnosed the decay as entering the dentin and restoration was necessary. During the restoration process, photographs were taken to visually document the depth of decay, based on appearance of decalcification of the enamel (evidenced as white material instead of normal, translucent enamel material) and staining of the dentin (brown spots). A clinical inspection also was performed with a mirror and probe to identify soft spots.

At the same time, BAD recorded surfaces which were caries-free or had proximal dental caries in the enamel that required monitoring and non-invasive treatment. This determination was based on direct inspection of adjacent surfaces. In cases where proximal dental caries was present in the enamel but BAD did not believe that restoration was required, the patient was advised to follow one or more of the following instructions: improve oral hygiene using brushing and especially flossing; change diet and minimize consumption of sweets, soft drinks, et cetera; use a daily fluoride rinse or daily fluoride tray treatment; and possibly use a recalcification product such as M1 Paste (GC America Inc.). The LCD software was used during follow-up visits to monitor the state of dental caries and to assess the effectiveness of these non-invasive measures, with the goal being to avoid restoring the suspect surfaces. 
Eighteen of BAD's patients presented bitewing images where one or more surfaces presented with dentinal decay that had been detected visually and/or with the LCD density analysis; the decay was not readily obvious on digital image and the surfaces had been, in the opinion of BAD, a challenge to detect and classify. In addition, cases had to demonstrate confirmed caries-free surfaces or surfaces where decay appeared to be in the enamel only. These latter surfaces had been monitored by BAD for several years to confirm their status. The type of treatment (restoration or noninvasive) was decided prior to any consideration of the images to be used in this study.

\section{Observers}

Twelve general dental practitioners with experience in diagnosing and treating proximal dental caries were recruited as observers. All observers were either full or parttime attending faculty from University of Louisville School of Dentistry (ULSD). The age of observers ranged from 40 years of age to 73 , with the average age being 55 . They have been practicing dentistry for an average of 27 years and have been teaching at ULSD for an average of 14 years. The observers viewed the set of 18 images independently, with no knowledge of which surfaces had been restored by BAD or which ones were designated as caries-free or with enamel caries only.

Each observer viewed the designated surfaces on the selected set of radiographs in each of the viewing conditions, both with and without LCD software. The evaluators were asked to identify each surface according to the following four point scale: 
$0=$ No caries present

$1=$ Caries less than halfway through the enamel

$2=$ Caries halfway or more through the enamel but not into the dentin

$3=$ Caries through the enamel and touching or entering the dentin

These numbers correlate with a radiographic classification of proximal dental caries (Fig. 3).

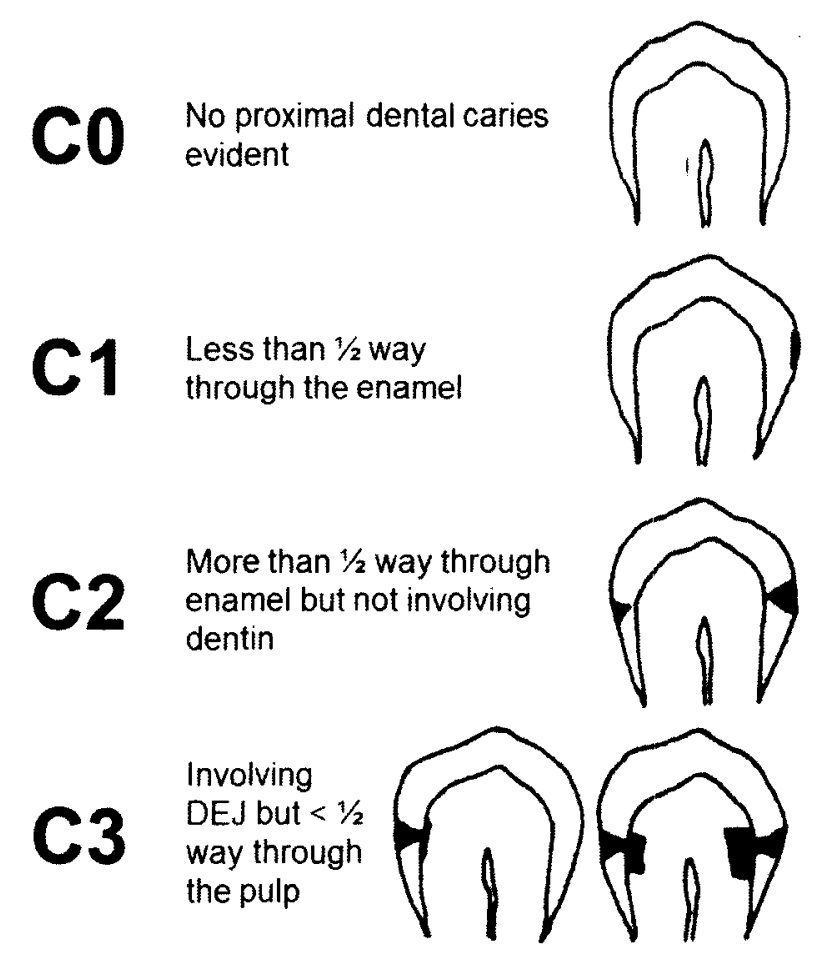

Figure 3. Radiographic classification of proximal dental caries used in the study.

The evaluators recorded their ratings on an Observer Answer Sheet for each condition (Appendix C). For each image viewed, there was a matching diagram on the answer sheet. Observers were asked to rate 5 to 15 surfaces per image. If the corresponding diagram on the answer sheet had 5 vacant spaces, the observer recorded 5 
answers. If the corresponding diagram had 10 vacant spaces, the observer recorded 10 answers. The answers were recorded by the principal investigator (LCS) on the mesial or distal surface on the diagram. If an $\mathrm{X}$ was displayed on the diagram, it indicated that the observer should not provide a rating for that surface. If a restoration was present on the viewed radiograph, a restoration was imitated on the diagram. If the restoration hindered diagnostic ability, an $\mathrm{X}$ was displayed on the answer sheet. No answer was provided for such space. If the restoration did not hinder diagnostic ability, observers recorded their answers normally. Fig. 4 and Fig. 5 show examples of the Observer Answer Sheet. Intra-observer agreement was assessed by having each observer view $25 \%$ of the images twice, with a one week interval between viewing conditions to eliminate memory bias.

Radiograph viewed on computer monitor
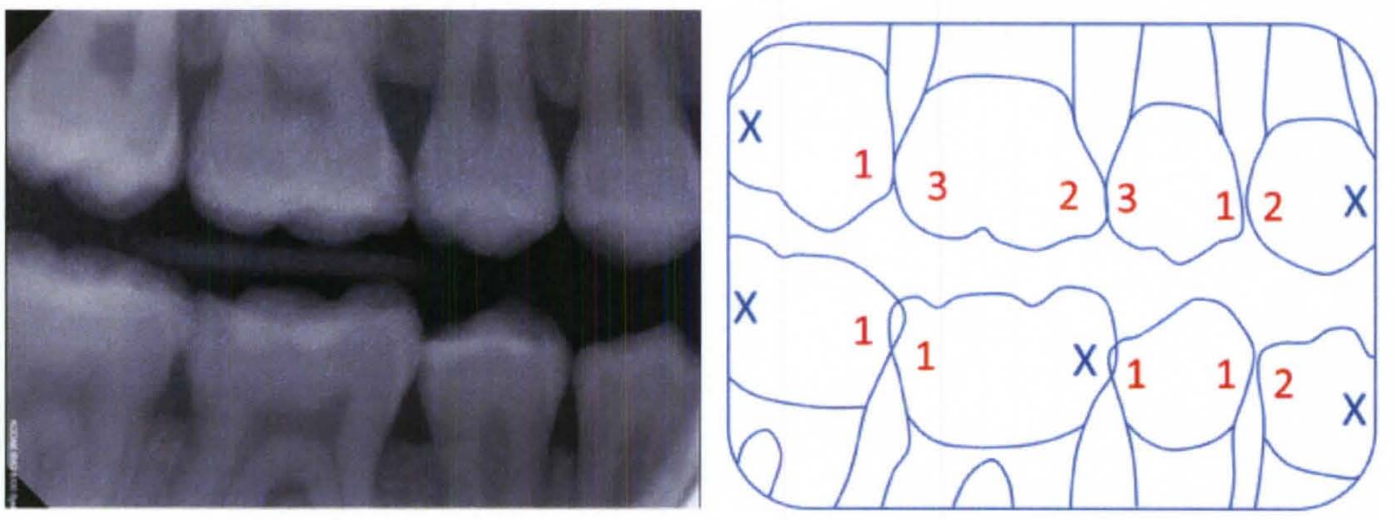

Figure 4. Example of Observer Answer Sheet. Reproduction of digital image (left) with corresponding diagram with example answers (right). 
Radiograph viewed on computer monitor
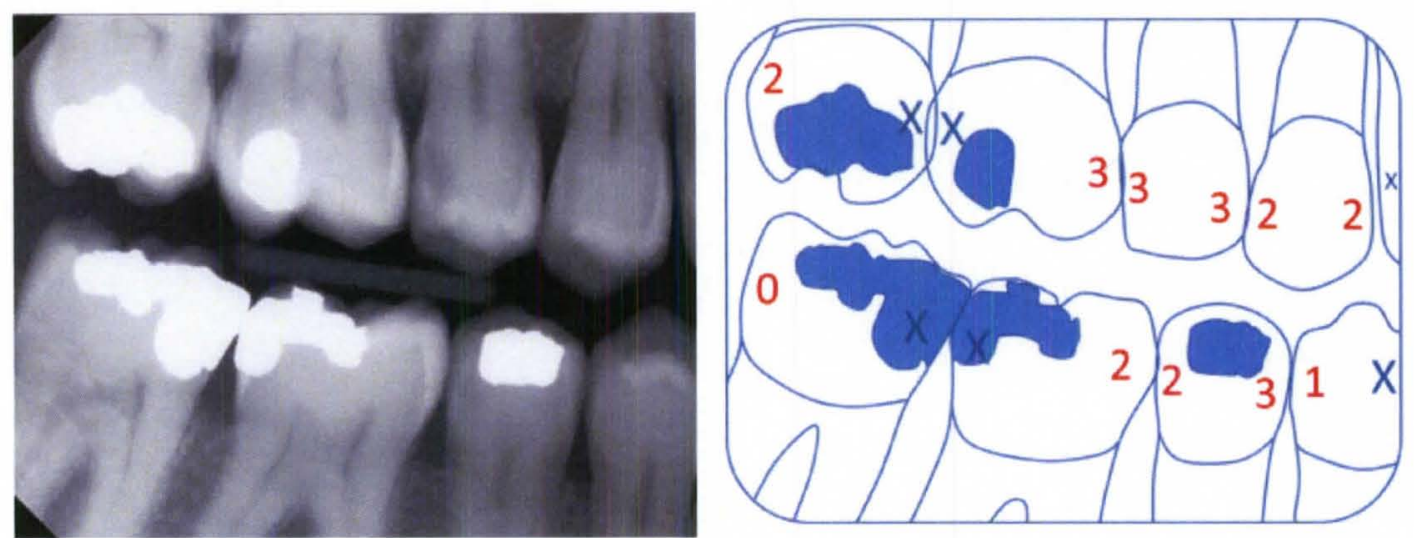

Figure 5. Example of Observer Answer Sheet diagram with restorations present.

Reproduction of digital image (left) with corresponding diagram with example answers (right).

\section{Viewing Conditions}

The digital images were evaluated under three conditions, and three subconditions. The same cubicle/chair was used for each observer to ensure continuity throughout. The condition is a physical location/setting in which the observer viewed the images. The subcondition is a modality in which the observer viewed/diagnosed the images. All images were viewed using the Logicon software. All monitors used were calibrated using the TG10-QC calibration pattern (Fig. 9)

\section{Conditions:}

1) Optimal condition - A darkened room with no ambient lighting: Physically this was the Radiology clinic reading room at ULSD with all lights turned off. The monitor used in this situation was a Dell 
Professional P2210H with 1920 x 1080 resolution (Dell Inc., Round Rock, TX, USA). (Fig. 6)

2) Clinical operatory - A brightly lit dental operatory with overhead fluorescent lighting. Physically, this was a cubicle in the dental clinic at ULSD with overhead fluorescent lights on. The monitor used in this situation was a ēlo Entūitive 1725L Touchmonitor (Elo Touch Solutions, Menlo Park, CA, USA). (Fig. 7)

3) Clinical operatory with infection control barriers - Physically, this was the same cubicle in the dental clinic at ULSD, however, with a clear infection control bag placed over the monitor. The same bag was used for each observer to ensure continuity. This situation is the standard protocol for chair-side interpretation and treatment at ULSD (Fig. 8)

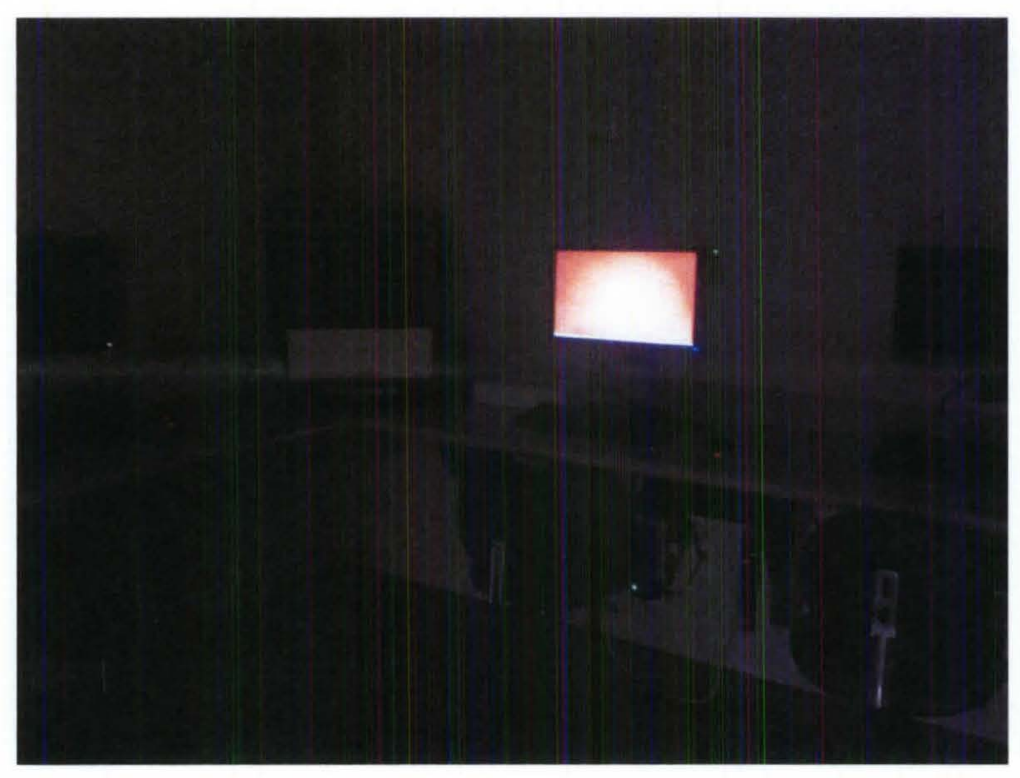

Figure 6. Dark Room viewing condition 


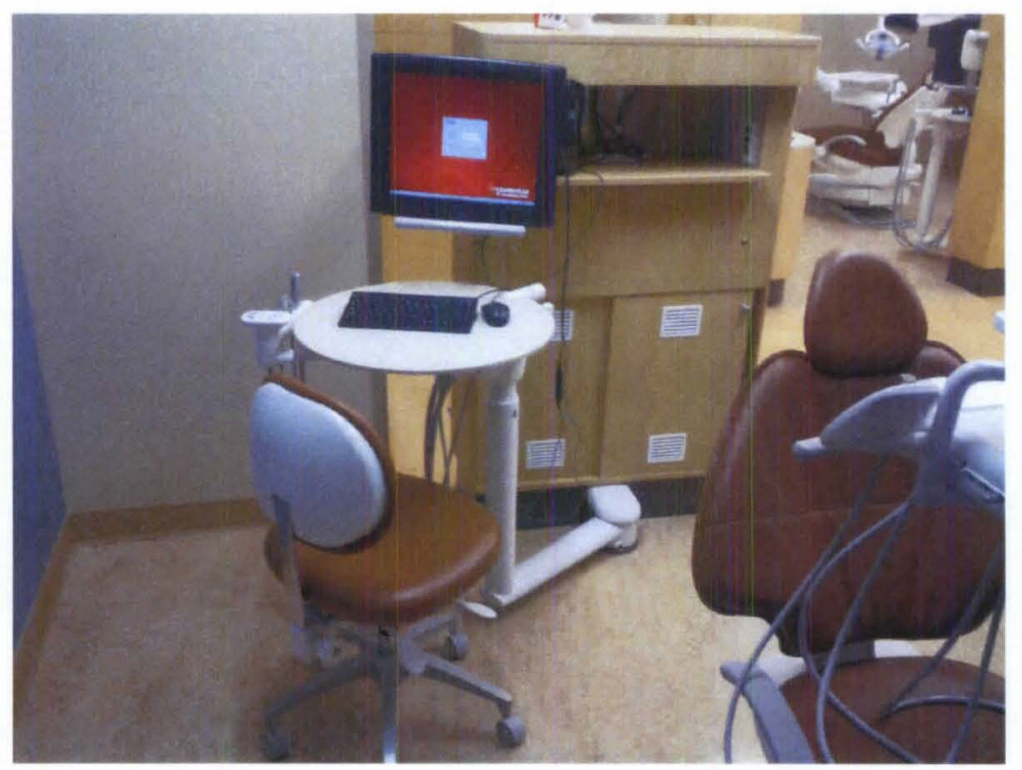

Figure 7. Clinical Operatory, Bright Room viewing condition

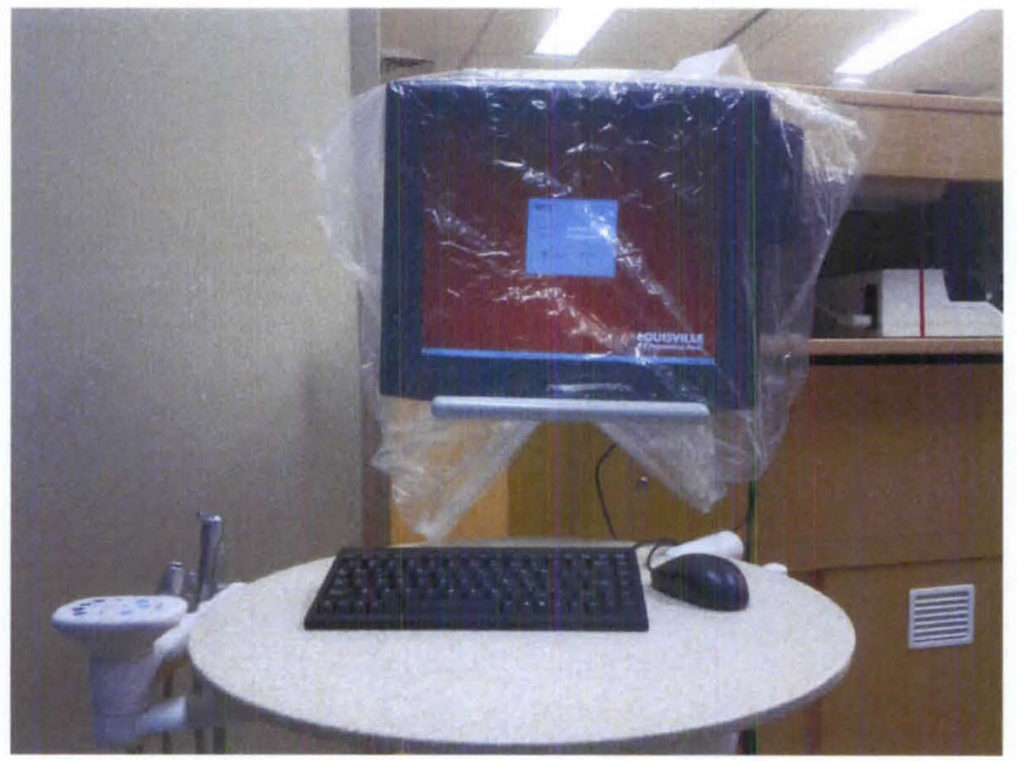

Figure 8. Protective Barrier viewing condition 


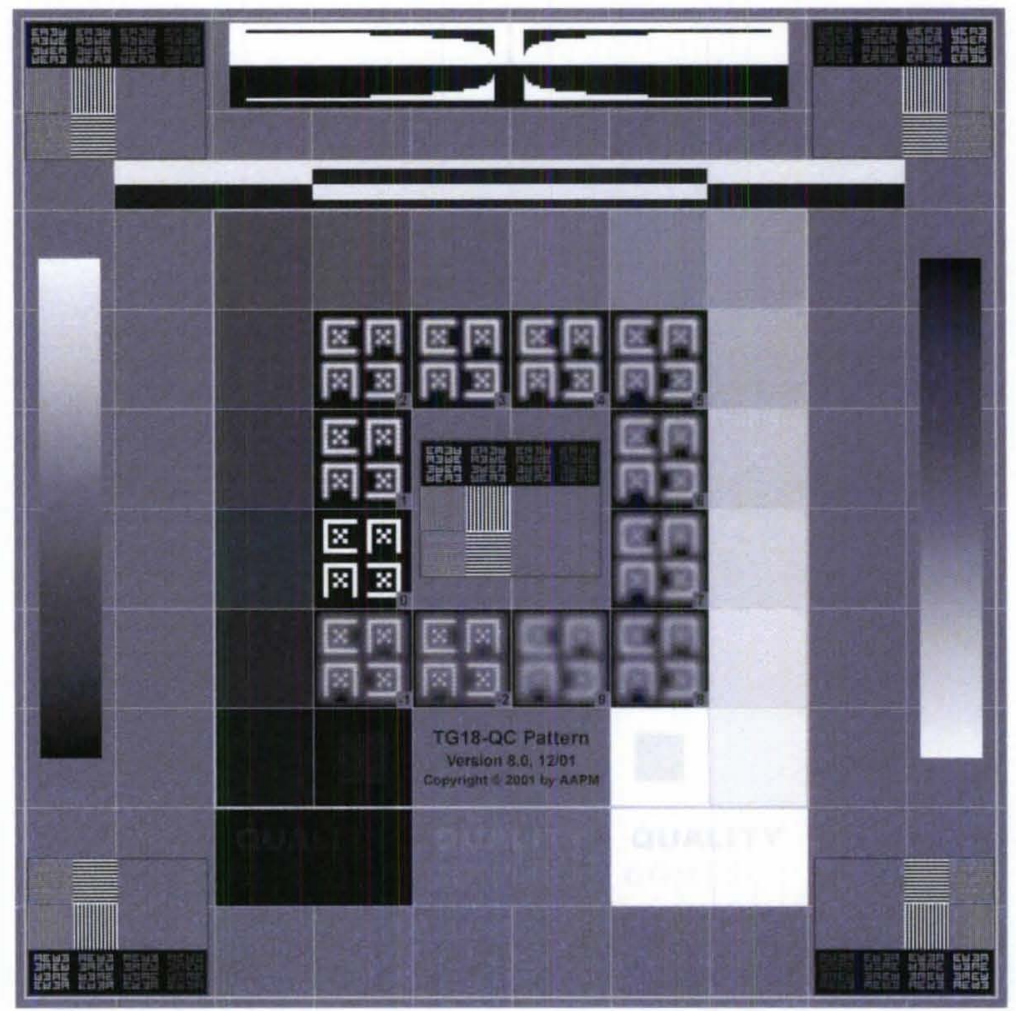

Figure 9. TG10-QC calibration pattern

\section{Sub-conditions:}

1) Unenhanced: Raw image with no enhancements

2) Sharpened: Image was sharpened to Level 1

3) Logicon: Observers ran the density analysis of LCD 
a.

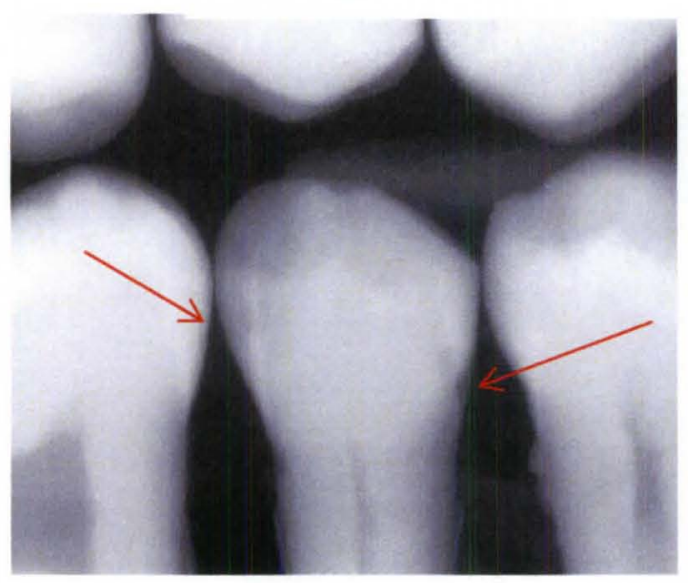

c.

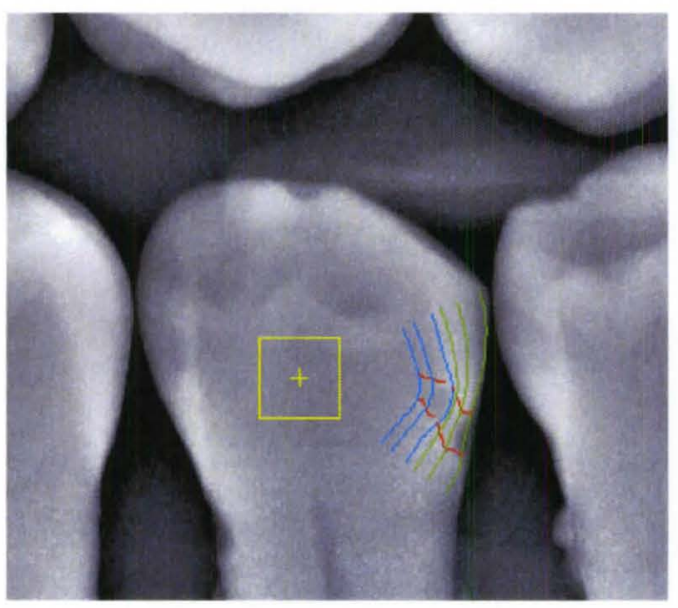

b.

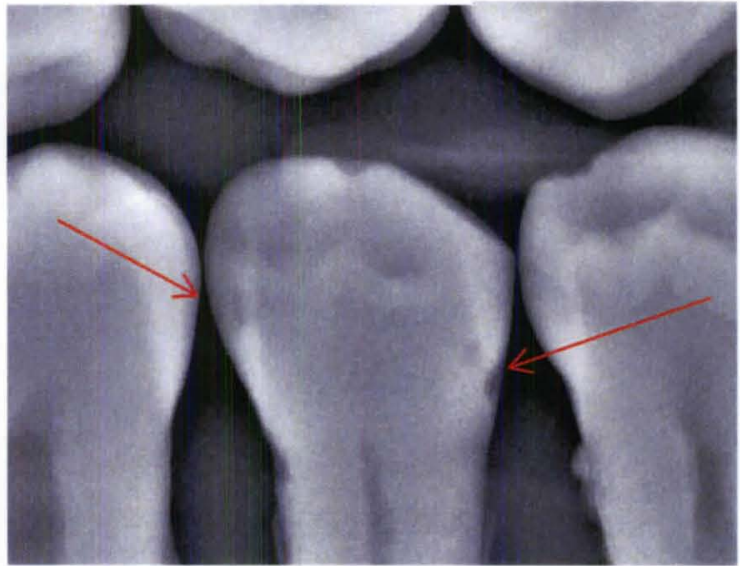

d.

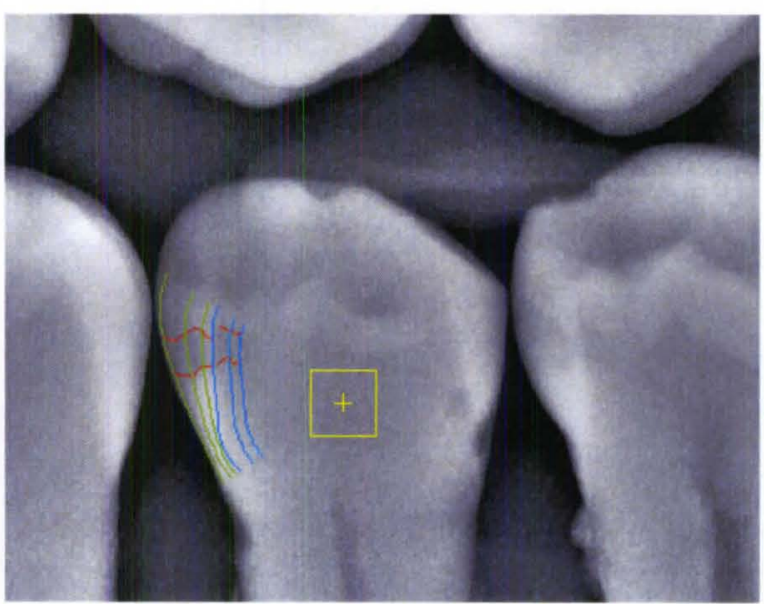

Figure 10. Examples of sub-conditions. A) Unenhanced image: Arrows point out proximal caries on $13 \mathrm{D}$ and $13 \mathrm{M}$ that could be difficult to detect. B) Image sharpened to Level 1 using Logicon. Arrows point out the same caries, which are now much clearer. C) LCD density analysis on $13 \mathrm{M}$ shows caries into the dentin. D) LCD density analysis on $13 \mathrm{D}$ also shows caries into the dentin. 


\section{Computer-assisted Software}

The observers were given a tutorial on how to use the LCD prior to evaluating any images with LCD. During this tutorial, observers were showed the proper techniques on using LCD density analysis, and how to interpret its results. Two images with 14 total surfaces were used as practice images during the tutorial. The PI had screenshot printouts of her density analysis of the practice images. The observers were able to compare their analyses with those of the PI. If the observer was using LCD improperly, or could improve their technique, the PI corrected them and/or gave tips to help the observer. This tutorial was the only time the PI was able to correct the observer. Once the study began, the PI did not correct the observers' LCD technique. The goal of the tutorial was to eliminate any problems and facilitate the study.

\section{Statistical Analysis}

The sensitivity, specificity, and accuracy of the observers overall were calculated for each of the viewing conditions and sub-conditions. The true statuses of caries were obtained from BAD after the study was completed. The true status was reported as a value $0-3$, in correlation with the evaluators' rating scale.

$0=$ No caries present

$1=$ Caries less than halfway through the enamel

$2=$ Caries halfway or more through the enamel but not into the dentin

$3=$ Caries through the enamel and touching or entering the dentin

The difference of the observers' ratings and the true status was calculated and used to determine sensitivity and specificity. 
| Observer Rating - True Status $\mid=$ Difference

Table 1: Statistical Ratings

\begin{tabular}{cccc}
\hline Difference & True Status & Observer Rating & Classification \\
\hline 0 or 1 & Caries-Free & Caries-Free & True Negative \\
2 or 3 & Caries-Free & Dentinal Caries & False Positive \\
0 or 1 & Dentinal Caries & Dentinal Caries & True Positive \\
2 or 3 & Dentinal Caries & Caries-Free & False Negative \\
\hline
\end{tabular}

Table 1 outlines the determination of true negatives and true positives based on the difference calculated from the equation above. If the difference of these two values was a 0 or 1 , and the true status of the surface was determined caries-free, it was a true negative, meaning the observer correctly rated the surface as having no caries present. If the difference was a 2 or 3 , and the true status of the surface was determined caries-free, it was a false positive, meaning the observer rated a healthy surface as having caries. If the difference was 0 or 1 , and the surface was caries-free, it was a true positive; the observer correctly rated the surface as having caries. Finally, if the difference was 2 or 3 , and the surface had dentinal caries, it is a false negative, meaning the observer rated a surface with dentinal caries as having no caries or enamel caries.

Using the formula below, the number of true positives and number of false negatives were used to calculate sensitivity. The number of true negatives and number of false positives were used to calculate specificity. 


$$
\text { Sensitivity }=\frac{\text { number of true positives }}{\text { number of true positives }+ \text { number of false negatives }}
$$

$$
\text { Specificity }=\frac{\text { number of true negatives }}{\text { number of true negatives }+ \text { number of false positives }}
$$

Using the sensitivities and specificities, accuracy was calculated using the formula below.

$$
\begin{gathered}
\text { Accuracy }= \\
{[\text { prevalence of disease } \times \text { sensitivity }]+[(1-\text { prevalence }) \times \text { specificity }]}
\end{gathered}
$$




\section{CHAPTER IV}

\section{RESULTS}

The true status of the surfaces was revealed once the study was complete. Based on the rating scale mentioned, a surface was classified as a 3 if the decay penetrated all the way through the enamel and touched or entered the dentin. A surface was classified as a 2 if the decay penetrated halfway or more through the enamel. Enamel penetration was judged based on depth of white decalcification. Dentin penetration was based on brown spots in the dentin. A surface was classified as a 0 if the dentist determined the surface clean over multiple patient visits. A surface was classified as a 1 if the dentist determined small surface caries, that were not worthy of restoration.

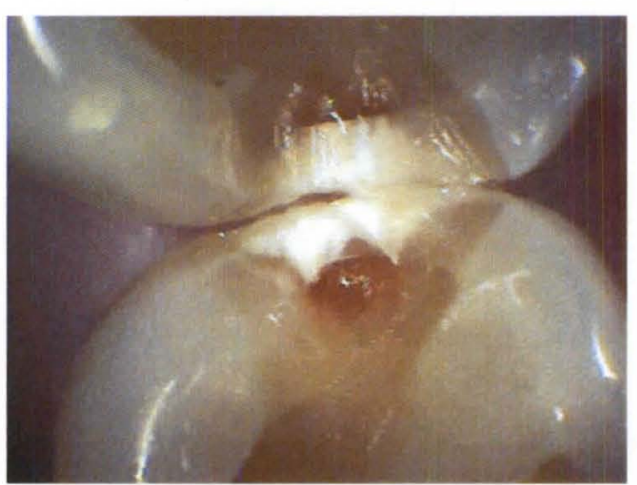

a.

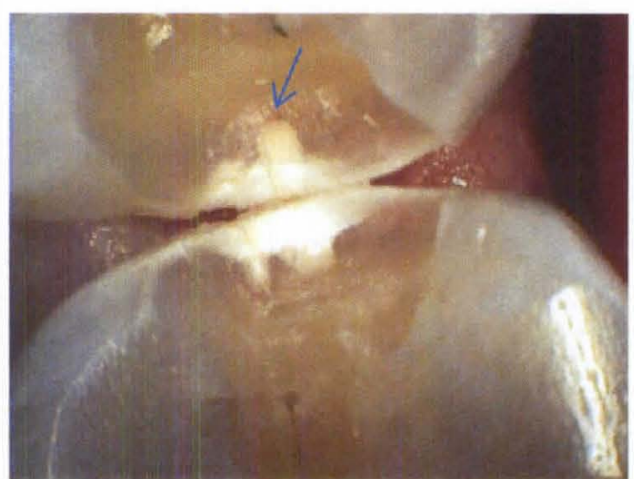

b. 


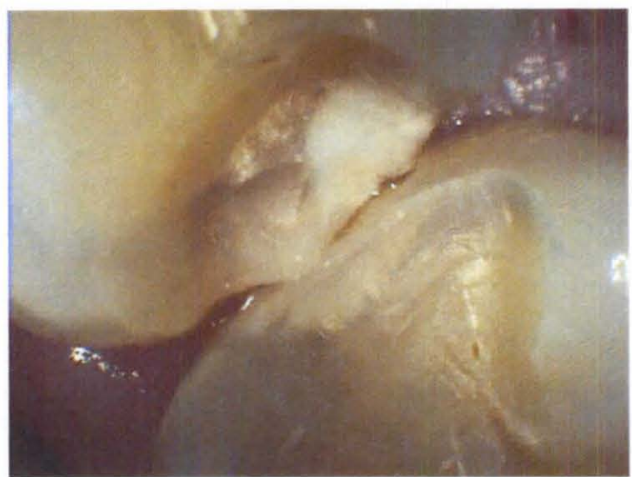

c.

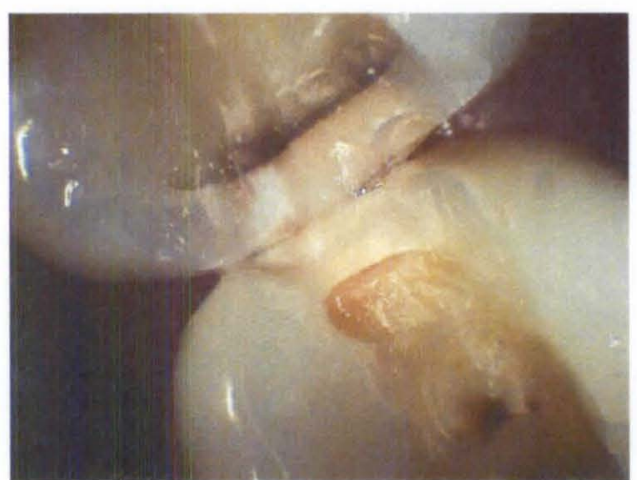

d.

Figure 11. Clinical confirmation of proximal dental carious status. a) White decalcification of enamel and brown spots in the dentin confirm dentinal caries of 12D (lower) and 13M. Both surfaces were rated as 3s. b) 12D (lower) and 13M of a different patient. Decay is clearly through the enamel in both cases. A very small brown spot is visible on $13 \mathrm{M}$. Both surfaces were rated as $3 \mathrm{~s}$. c) Decay is nearly through the enamel on $3 \mathrm{M}$ (upper), and was rated as a 3 . Decay appears through the enamel on $4 \mathrm{D}$, but no damage in dentin is visible (rated as a 2). d) $3 \mathrm{M}$ (upper) and 4D (lower). Decay is clearly through the enamel and into dentin for $3 \mathrm{M}$, and through the enamel for $4 \mathrm{D}$, both rated as $3 \mathrm{~s}$.

Of the 18 digital images, a total of 214 surfaces were used. Forty-one (41) surfaces were determined to have dentinal caries (rated as $3 \mathrm{~s}$ ), three surfaces were rated as $2 \mathrm{~s}$, one surface was rated as a 1 , and 5 surfaces were confirmed as caries free (rated as 0s). 
Table 2: Sensitivity-True Positive Rate

\begin{tabular}{cccc}
\hline & $\begin{array}{c}\text { Unenhanced } \\
\text { Image }\end{array}$ & $\begin{array}{c}\text { Sharpened } \\
\text { Level 1 }\end{array}$ & $\begin{array}{c}\text { Logicon Density } \\
\text { Analysis }\end{array}$ \\
\hline Bright Room & $\mathbf{8 5 . 8}$ & $\mathbf{8 7 . 0}$ & 99.5 \\
Dark Room & $\mathbf{8 5 . 9}$ & $\mathbf{8 6 . 6}$ & $\mathbf{9 9 . 2}$ \\
\hline $\begin{array}{l}\text { Bright Room with } \\
\text { Protective Barrier }\end{array}$ & $\mathbf{8 2 . 3}$ & $\mathbf{9 0 . 9}$ & $\mathbf{9 8 . 7}$ \\
\hline
\end{tabular}

Table 3: Specificity - True Negative Rate

\begin{tabular}{cccc}
\hline & $\begin{array}{c}\text { Unenhanced } \\
\text { Image }\end{array}$ & $\begin{array}{c}\text { Sharpened } \\
\text { Level 1 }\end{array}$ & $\begin{array}{c}\text { Logicon Density } \\
\text { Analysis }\end{array}$ \\
\hline Bright Room & $\mathbf{7 6 . 4}$ & $\mathbf{6 9 . 7}$ & $\mathbf{6 8 . 3}$ \\
Dark Room & $\mathbf{7 5 . 0}$ & $\mathbf{5 6 . 7}$ & $\mathbf{7 7 . 8}$ \\
$\begin{array}{l}\text { Bright Room with } \\
\text { Protective Barrier }\end{array}$ & $\mathbf{7 4 . 1}$ & $\mathbf{4 8 . 1}$ & $\mathbf{7 2 . 2}$ \\
\hline
\end{tabular}

Table 4. Accuracy

\begin{tabular}{cccc}
\hline & $\begin{array}{c}\text { Unenhanced } \\
\text { Image }\end{array}$ & $\begin{array}{c}\text { Sharpened } \\
\text { Level 1 }\end{array}$ & $\begin{array}{c}\text { Logicon Density } \\
\text { Analysis }\end{array}$ \\
\hline Bright Room & $\mathbf{8 4 . 7 \%}$ & $\mathbf{8 4 . 9 \%}$ & $\mathbf{9 5 . 8 \%}$ \\
Dark Room & $\mathbf{8 4 . 6 \%}$ & $\mathbf{8 3 . 0} \%$ & $\mathbf{9 6 . 6 \%}$ \\
$\begin{array}{c}\text { Bright Room with } \\
\text { Protective Barrier }\end{array}$ & $\mathbf{8 1 . 3 \%}$ & $\mathbf{8 5 . 8} \%$ & $\mathbf{9 5 . 5 \%}$ \\
\hline
\end{tabular}


Table 2 outlines the sensitivity calculated for each of the conditions and subconditions. For the unenhanced images, the true positive rate was as expected; diagnostic ability of observers was best in the dark room (85.9\%), followed closely by the bright room $(85.8 \%)$, and was significantly worse with the infection control barrier over the monitor $(82.3 \%)$. The second column shows that, overall, the sharpened image results in greater sensitivity than the unenhanced image. However, the viewing conditions did not comply with the hypothesis. There was greater diagnostic ability with the protective barrier $(90.9 \%)$ than the bright room alone $(87.0 \%)$, and the dark room was just slightly lower than that $(86.6 \%)$. It was expected to be the exact opposite, with dark room being the best and bright room with protective barrier being the worst. Finally, the third column shows that the use of Logicon Caries Detector produces a very large increase in diagnostic ability, with true positive rates being just shy of 100 percent.

Table 3 outlines the specificity for each of the conditions and sub-conditions. For the unenhanced images, the Bright Room proved to be the best condition, contrary to the hypothesis, with a true negative rate of $76.4 \%$. The Dark Room and Protective Barrier conditions followed behind with specificities of $75.0 \%$ and $74.1 \%$ respectively. The sharpened images followed the same pattern as the unenhanced images, with the bright room yielding the greatest specificity (69.7\%). Finally, the Logicon Caries Detector had scattered results, with the dark room having the largest specificity (77.8\%), and the bright room having the lowest $(68.3 \%)$.

When sensitivity and specificity are combined with prevalence, the accuracy (Table 4) shows a more consistent result. For the unenhanced image, the Bright and Dark rooms ( $84.7 \%$ and $84.6 \%$, respectively) proved to be superior to the Protective Barrier 
condition $(81.3 \%)$. The sharpened condition was different than anticipated, with the Protective Barrier condition having the greatest accuracy at $85.8 \%$, and the Dark Room having the lowest accuracy at $83.0 \%$. Finally, the LCD proved to have much greater accuracy than the unenhanced and sharpened images, regardless of condition. 


\section{CHAPTER V \\ DISCUSSION}

\section{Purpose and Motivation}

This study found that overall diagnostic ability of observers in identifying restorable proximal dental caries decreases in poor viewing conditions. In such conditions when poor lighting and/or infection control barriers can obscure visualization of the monitor, we found computer assisted software, like Logicon Caries Detector, can restore or improve the unaided detection of restorable proximal dental caries.

Overall, it was found that computer assisted software increased diagnostic ability by up to 16.4 percent. In addition, we found detection rates are consistent and unaltered by sub-optimal viewing conditions. This is most likely because the software program analyzes the raw image, without input from the human visual system, and therefore is uninfluenced by surrounding viewing conditions; the variability of the sensitivity results is solely based on the users' ability to pinpoint the surface in question and how they interpret the results.

The data also proves that the protective plastic barriers for infection control over the monitors in the clinical operatory decreases diagnostic ability. In two of the three subconditions, the barrier condition resulted with the lowest sensitivity. The Sharpened 
Level 1 condition was an anomaly with sensitivity being $4 \%$ higher than the Dark and Bright Room conditions.

It was expected that in the Darkened Room, observers would perform much better than in the Bright Room. In all three sub-conditions, the sensitivity values for Dark and Bright Rooms were almost identical. Therefore, it is not possible to say one condition is significantly better than the other.

Inferences from the specificity data, however, are difficult to establish. The use of LCD was not as consistent as with sensitivity. The determination of true negatives ranged almost $10 \%$, from $68.3 \%$ to $77.8 \%$, with the Darkened Room being the highest. This could be due to user error of the software or the observers improperly interpreting the results LCD provided.

In the Sharpened and Unenhanced sub-conditions, the protective barrier condition proved to be the worst, which was consistant with the sensitivity, and with the hypothesis. Contrary to the hypothesis, the Bright Room resulted as the condition with the greatest specificity, significantly larger than the Dark Room. Also contrary to the hypothesis, the Unenhanced images had a greater specificity than the sharpened images.

The inconsistent results for specificity may be partially explained by the lack of true negative, or caries-free, data. Of the 50 surfaces that had confirmed status, only six of them were classified as caries-free. This small number of surfaces, as with any type of analysis, caused the specificity data to be scattered. For example, changing the ratio of "diseased to disease-free" to 44 diseased and 44 disease-free would also influence overall accuracy.

e.g. Accuracy for bright room unenhanced with prevalence of 44 diseased and 6 
non-diseased $=\left[\frac{\mathbf{4 4}}{\mathbf{5 0}} \times \mathbf{8 5 8}\right]+\left[\left(1-\frac{\mathbf{4 4}}{\mathbf{5 0}}\right) \times .764\right]=\mathbf{8 4 . 7} \%$ Accuracy for bright room unenhanced with prevalence of 44 diseased and 44 non-diseased $=$ $\left[\frac{44}{88} \times .858\right]+\left[\left(1-\frac{44}{88}\right) \times .764\right]=81.1 \%$

\section{Future Areas of Research}

Future research could include a similar analysis of diagnostic ability of proximal dental caries, using a greater number of confirmed caries-free surfaces. It is now clear that it cannot be expected to obtain confirmed caries surfaces and caries-free surfaces from the same patient radiographs. When digital dental images have several surfaces with confirmed caries, these patients usually have very poor teeth and no credible cariesfree surfaces. For future research, it would be wise to select patients with no history of caries, in addition to the patients with poor teeth. This would call for a larger selection size, but would result in more credible data. 


\section{CHAPTER VI}

\section{CONCLUSION}

When working in a clinical setting with protective infection control barriers on the monitors, as is done at University of Louisville School of Dentistry, the viewing condition for diagnosing digital radiographs is sub-optimal. It is important for dentists to familiarize themselves with conditions in which their diagnostic ability is best. In this study, it was not possible to declare a bright room (dental clinic) or a dark room with no ambient lighting (radiology clinic) as being a more optimal condition. However, it was proven that when using protective barriers on the computer monitors, diagnostic ability significantly decreased. Therefore, when practicing in such setting, it would be recommended that the dentist remove protective barriers from the monitor when interpreting digital radiographs for the presence of proximal dental caries.

Computer assisted diagnosis (e.g. LCD) for proximal dental caries provides optimal accuracy regardless of viewing condition. $55.6 \%$ of the observers found Logicon easy to use, and $66.7 \%$ of the observers said they would use LCD in private practice or would like to see it implemented at ULSD. When asked what the observers liked about Logicon, they said they liked how accurate it was, and how it could detect caries that could have otherwise gone undetected, or "under"-detected. They liked that it could identify decay in non-suspect areas and that it gave positive reinforcement to 
questionable lesions. When asked what they disliked about LCD, they said there was a steep learning curve at the beginning, but they liked it after some practice. They also disliked that it was time consuming. However, it can be argued that the extra time spent using LCD is worth the accurate diagnosis.

Advancements in digital dental intraoral radiography have created opportunities to enhance digital images and to incorporate computer assisted diagnostic software into their office to assist with detection of proximal dental caries. It has been demonstrated that Logicon Caries Detector enabled dentists to find $17 \%$ more dentinal caries than unaided diagnosis, without misdiagnosing healthy surfaces. This same program can be used to monitor healthy surfaces and surfaces with enamel caries over time to see if noninvasive treatments are helping, and are preventing the surfaces from decaying further. 


\section{REFERENCES}

1. Bartoloni JA, Chao SY, Martin GC, Caron GA. Dental caries risk in the U.S. Air Force. J Am Dent Assoc. 2006;137:1582-1591.

2. Bader J, Shugars D. A Systematic Review of the Performance of a Laser Fluorescence Device for Detecting Caries. J Dent Educ. 2004;135:14131425.

3. GAKENHEIMER DC. The efficacy of a computerized caries detector in intraoral digital radiography. $J$ Am Dent Assoc. 2002;133:883-890.

4. Ludlow J, Ivanovic M. Comparative dosimetry of dental CBCT devices and 64slice CT for oral and maxillofacial radiology. Oral Surg Oral Med Oral Pathol Oral Radiol Endod. 2008;106:106-114.

5. Dykstra B. Interproximal Caries Detection: How Good Are We? Dentistry Today. 2008.

6. Tracy KD DB, Gakenheimer DC, PhD, Scheetz JP, Lacina S, Scarfe WC, Farman AG. Utility and effectiveness of computer-aided diagnosis of dental caries. General Dentistry. 2011;59:136-144.

7. Haiter-Neto F, Wenzel A, Gotfredsen E. Diagnostic accuracy of cone beam computed tomography scans compared with intraoral image modalities for detection of caries lesions. Dentomaxillofac. Radiol. 2008;37:18-22.

8. Bader J, Shugars D, Bonito A. Systematic reviews of selected dental caries diagnostic and management methods. $J$ Dent Educ. 2001;65:960-968.

9. Horowitz AM. A Report on the NIH Consensus Development Conference on Diagnosis and Management of Dental Caries Throughout Life. Journal of Dental Research. 2004;83:C15-17.

10. Louisana State University SoD. Chapter 5: Dental Caries2011.

11. Kimpe $T$, Tuytschaever $T$. Increasing the number of gray shades in medical display systems--how much is enough? J Digit Imaging. Dec 2007;20:422-432. 
$\underline{\text { Informed Consent Document }}$

For IRB Approval Stamp

The Effect of Viewing Conditions on the Detection of Proximal Dental Caries in Intraoral Digital Images with and without Computer-assisted Diagnostic Software

Investigators names \& addresses:

Lauren C. Szechy, BS ${ }^{1}$

William C. Scarfe BDS, FRACDS, MS, Dipl. ABOMR ${ }^{1}$

Allan G. Farman BDS, PhD, EdS, MBA, DSc, Dipl. ABOMR, Dipl. JBOMR ${ }^{1}$

Bradley A. Dykstra, DDS, MBA ${ }^{2}$

David C. Gakenheimer, PhD $^{3}$

${ }^{1}$ University of Louisville School of Dentistry, Louisville, KY; ${ }^{2}$ Hudsonville Dental Associates, Hudsonville, MI;

${ }^{3}$ PracticeWorks Systems, LLC, subsidiary of Carestream Health, Inc., Rancho Palos Verdes, CA.

Site where study is to be conducted:

University of Louisville School of Dentistry

501 S. Preston Street

Louisville, KY

Phone number for subjects to call for questions:

(502) $852-1226$

\section{Introduction and Background Information}

You are invited to participate in a research study. The study is being conducted by Professors William C. Scarfe BDS, FRACDS, MS, and Allan G. Farman BDS, Ph.D, DSc and Candidate in the Masters in Oral Biology program, Ms. Lauren C. Szechy, BS. The study is sponsored the University of Louisville School of Dentistry (ULSD). The study will take place at ULSD. Approximately fifteen observers will be invited to participate.

\section{Purpose}

The purpose of this study is to compare observers' diagnostic ability of proximal dental caries detection on digital intraoral radiographic images under different viewing conditions both with and without the aid of computer-assisted software. 


\section{Procedures}

In this study, you will be asked to evaluate a set of 20 radiographic digital images under multiple viewing conditions both with and without computer-assisted software. Each viewing condition will necessitate a separate viewing session. There will be at least a week interval between viewing conditions to eliminate memory bias. Each viewing session is estimated to take between one and two hours. The images are a series of noncommercial clinical bitewings from de-identified patients and will be codified A-T. For each image, there will be from 5 to up to 15 proximal surfaces that you be asked to evaluate. For each surface, you will be asked to record your confidence of proximal caries being present or absent based on a five point scale.

\section{Potential Risks}

There are no foreseeable risks, although there may be unforeseen risks.

\section{Benefits}

The possible benefits of this study include learning about factors and variability in detection of proximal dental caries, the importance of viewing conditions, and under what conditions computer-assisted diagnostic software can be beneficial in clinical dental practice. The information collected may not benefit you directly. The information learned in this study may be helpful to others.

\section{Confidentiality}

Your privacy will be protected to the extent permitted by law. Your individual responses will be codified and de-identified such that your identity will, in no way, be linked to your responses. If the results from this study are published, your name will not be made public. While unlikely, the following may look at the study records:

The University of Louisville Institutional Review Board, Human Subjects Protection Program Office, Office for Human Research Protections (OHRP), and the Office of Civil Rights

\section{Voluntary Participation}

Taking part in this study is voluntary. You may choose not to take part at all. If you decide to be in this study you may stop taking part at any time. If you decide not to be in this study or if you stop taking part at any time, you will not lose any benefits for which you may qualify. 


\section{Research Subject's Rights, Questions, Concerns, and Complaints}

If you have any concerns or complaints about the study or the study staff, you have three options.

You may contact the principal investigator at (502) 852-1226.

If you have any questions about your rights as a study subject, questions, concerns or complaints, you may call the Human Subjects Protection Program Office (HSPPO) (502) 852-5188. You may discuss any questions about your rights as a subject, in secret, with a member of the Institutional Review Board (IRB) or the HSPPO staff. The IRB is an independent committee composed of members of the University community, staff of the institutions, as well as lay members of the community not connected with these institutions. The IRB has reviewed this study.

If you want to speak to a person outside the University, you may call 1-877-8521167 . You will be given the chance to talk about any questions, concerns or complaints in secret. This is a 24 hour hot line answered by people who do not work at the University of Louisville.

This paper tells you what will happen during the study if you choose to take part. Your signature means that this study has been discussed with you, that your questions have been answered, and that you will take part in the study. This informed consent document is not a contract. You are not giving up any legal rights by signing this informed consent document. You will be given a signed copy of this paper to keep for your records.

Signature of Subject/Legal Representative

Date Signed

Signature of Investigator

Date Signed

LIST OF INVESTIGATORS

Dr. William C. Scarfe

Dr. Allan G. Farman

Ms. Lauren C. Szechy
PHONE NUMBERS

(502) $852-1226$

(502) $852-1241$

(440) $503-5238$
For IRB Approval Stamp

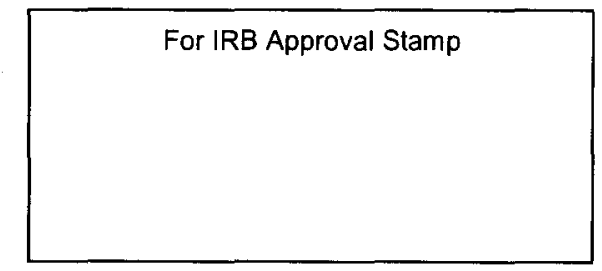




\section{APPENDIX B}

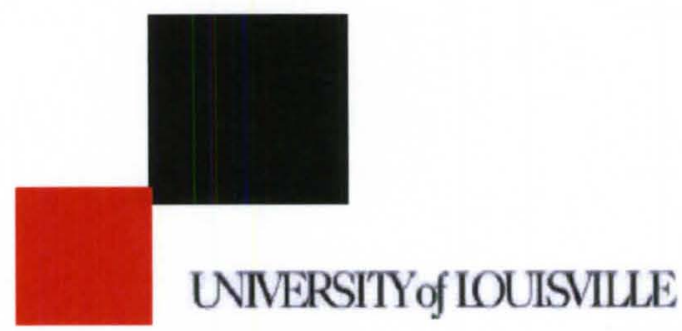

INSTITUTIONAL REVIEW BOARDS

University of Louisville

MedCenter One, Suite 200

501 E. Broadway

Louisville, Kentucky 40202-1798

Office: $\quad 502-852-5188$

Fax: $\quad 502-852-2164$

To: $\quad$ Scarfe, William

From: $\quad$ The University of Louisville Institutional Review Board (IRB)

Date: $\quad$ Monday, April 02, 2012

Subject: Approval Letter

Tracking \#: 11.0630

Title: $\quad$ The Effect of Viewing Conditions on the Detection of Proximal Dental Caries in Intraoral Digital Images with and without Computer-assisted Diagnostic Software

Approval 3/29/2012 12:00:00 AM

Date:

Expiration 3/28/2013 12:00:00 AM

Date:

The revised document(s) for the above referenced study have been received and contain the changes requested in our letter of $2 / 24 / 2012$. This study was reviewed on $3 / 29 / 2012$ by the chair/vice chair of the Institutional Review Board (IRB) and approved through the Expedited Review Procedure, according to 45 CFR 46.110(b), since this study falls under Expedited Category (7) Research on individual or group characteristics or behavior (including, but not limited to, research on perception, cognition, motivation, identity, language, communication, cultural beliefs or practices, and social behavior) or research employing survey, interview, oral history, focus group, program evaluation, human factors evaluation, or quality assurance methodologies.

The following items have been approved:

- Protocol, not dated

- Informed Consent, dated 3/24/2012 
This study now has final IRB approval from $3 / 29 / 2012$ through $3 / 28 / 2013$. You should complete and return the Progress Report/Continuation Request Form EIGHT weeks prior to this date in order to ensure that no lapse in approval occurs. The committee will be advised of this action at their next full board meeting.

Site Approval

If this study will take place at an affiliated research institution, such as Jewish Hosvital/St Marvs Hosbital. Norton Healthcare. or Universitv of Louisville Hosbital. permission to use the site of the affiliated institution may be necessary before the research may begin. If this study will take place outside of the University of Louisville Campuses, permission from the organization should be obtained before the research may begin. Failure to obtain this permission may result in a delay in the start of your research.

Privacy \& Encryption Statement

The University of Louisville's Privacy and Encryption Policy requires such information as identifiable medical and health records: credit card, bank account and other personal financial information; social security numbers; proprietary research data; dates of birth (when combined with name, address and/or phone numbers) to be encrypted. For additional information: http://security.louisville.edu/PolStds/ISO/PS018.htm.

1099 Information (If Applicable)

As a reminder, in compliance with University policies and Internal Revenue Service code, all payments (including checks, gift cards, and gift certificates) to research subjects must be reported to the University Controller's Office. Petty Cash payments must also be monitored by the issuing department and reported to the Controller's Office. Before issuing compensation, each research subject must complete a $\mathrm{W}-9$ form.

For additional information, please contact the Controller's Office at $852-8237$ or contro II@louisville.edu.

The following is a NEW link to an Instruction Sheet for BRAAN2 "How to Locate Stamped/Approved Documents in BRAAN2":

http://louisville.edu/research/braan2/help/ApprovedDocs.pdf/view

Please begin using your newly approved (stamped) document(s) at this time. The previous versions are no longer valid. If you need assistance in accessing any of the study documents, please feel free to contact our office at (502) 852-5188. You may also email our service account at hsppofc@louisville.edu for assistance.

Best wishes for a successful study. If you have any questions please contact the HSPPO at (502) 852-5188 or hsppofc@louisville.edu.

Thank you.

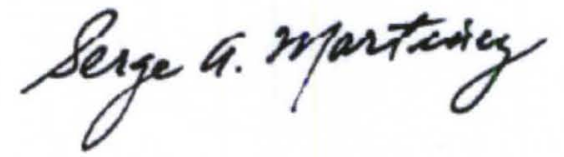

Board Designee: Martinez, Serge 
Once you begin your human subject research the following regulations apply:

1. Unanticipated problems or serious adverse events encountered in this research study must be reported to the IRB within five (5) work days.

2. Any modifications to the study protocol or informed consent form must be reviewed and approved by the IRB prior to implementation.

3. You may not use a modified informed consent form until it has been approved and validated by the IRB.

4. Please note that the IRB operates in accordance with laws and regulations of the United States and guidance provided by the Office of Human Research Protection (OHRP), the Food and Drug Administration (FDA), the Office of Civil Rights (OCR) and other Federal and State Agencies when applicable.

5. You should complete and SUBMIT the Continuation Request Form eight weeks prior to this date in order to ensure that no lapse in approval occurs.

Letter Sent By: Carnell, Nadine, 4/2/2012 2:00 PM

Full Accreditation since June 2005 by the Association for the Accreditation of Human Research Protection Programs, Inc.

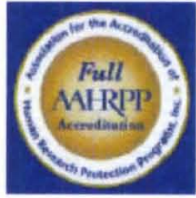




\section{APPENDIX C}

\section{Instructions:}

\section{OBSERVER ANSWER SHEET}

Each image that you will view will be accompanied by a matching diagram on the answer sheet. For each image, you will examine 5 to 15 interproximal surfaces. If the corresponding diagram on your answer sheet has 5 vacant spaces, you will record 5 answers. If the corresponding diagram has 10 vacant spaces, you will record 10 answers. Record your answer on the mesial or distal surface on the diagram as indicated. If an $\mathrm{X}$ is present on a surface, do not record an answer for such space. Refer to the example below.

If at any point you become confused, or if the film image does not match with the diagram on your answer sheet, stop immediately and notify the coordinator.

\section{Possible answers:}

$0=$ No caries present

$1=$ Caries less than halfway through the enamel

$2=$ Caries halfway or more through the enamel but not into the dentin

$3=$ Caries through the enamel and touching or entering the dentin

\section{Example:}

Radiograph viewed on computer monitor
Corresponding diagram with example answers

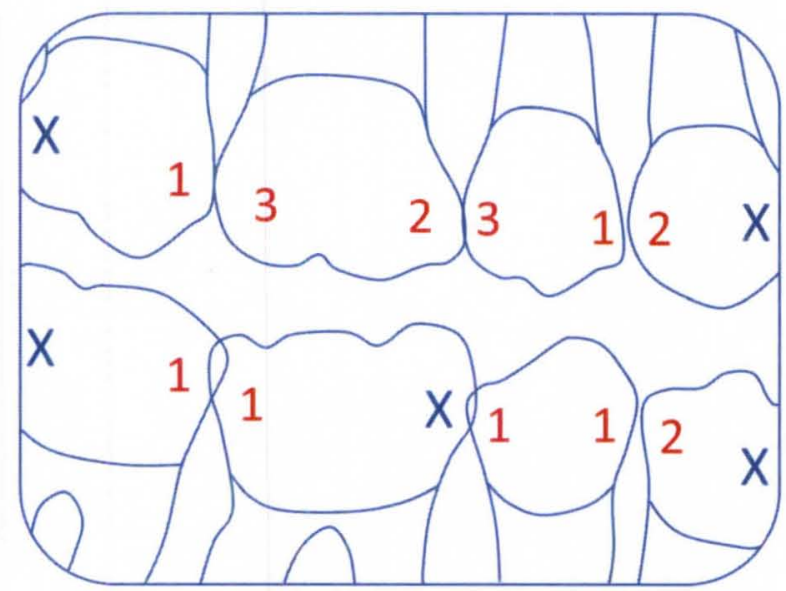


If a restoration is present on the viewed radiograph, a restoration will be imitated on the diagram. If the restoration hinders your diagnostic ability, there will be an X; do not provide an answer for such space. If the restoration does not hinder your diagnostic ability, record your answer normally. Refer to the example below.

\section{Example:}

Radiograph viewed on computer monitor

Corresponding diagram with example answers
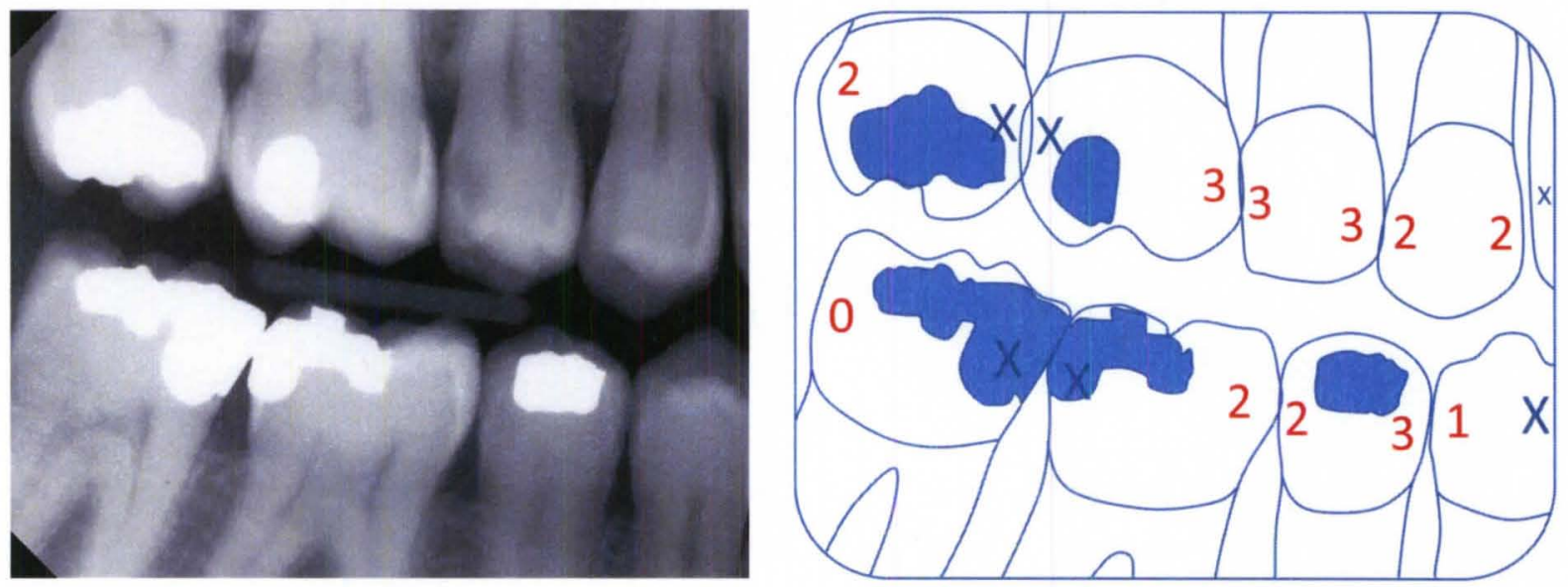


\section{OBSERVER ANSWER SHEET}

Observer name:

Viewing condition:

\section{Possible answers:}

$0=$ No caries present

$1=$ Caries less than halfway through the enamel

$2=$ Caries halfway or more through the enamel but not into the dentin

$3=$ Caries through the enamel and touching or entering the dentin

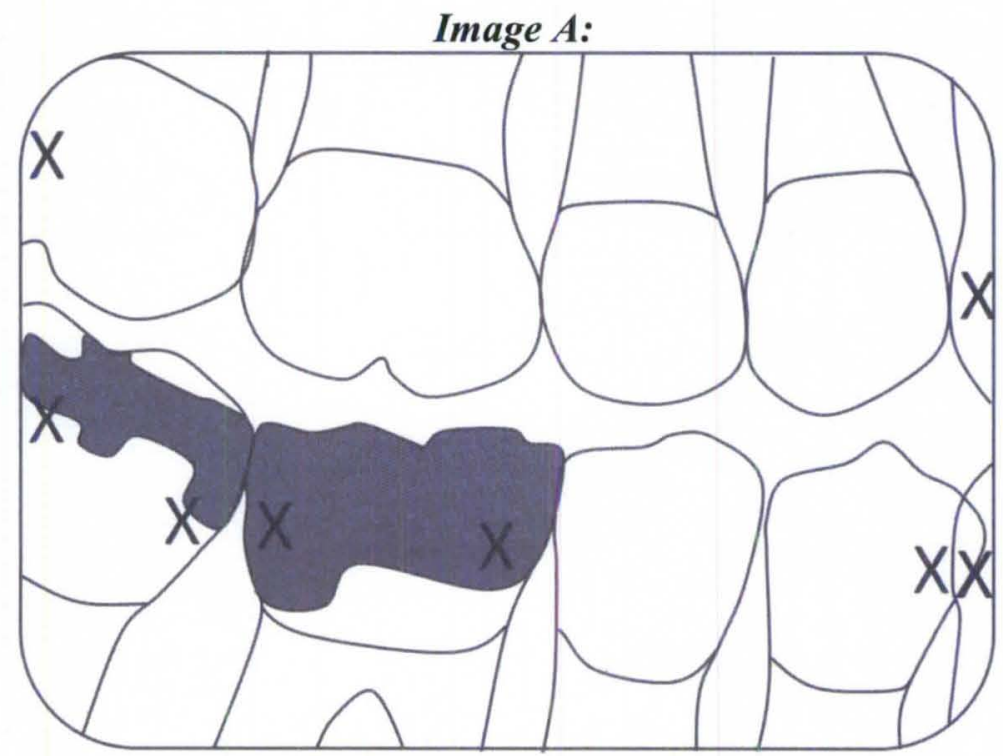

Image B:

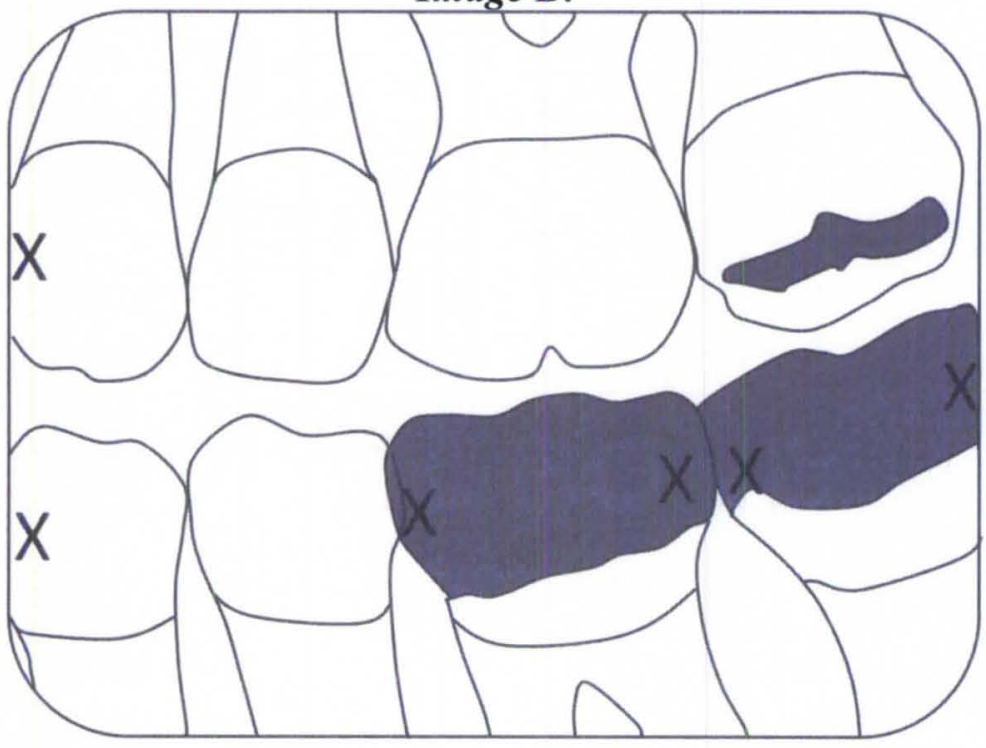




\section{OBSERVER ANSWER SHEET}

Observer name:

Viewing condition:

\section{Possible answers:}

$0=$ No caries present

$1=$ Caries less than halfway through the enamel

$2=$ Caries halfway or more through the enamel but not into the dentin

$3=$ Caries through the enamel and touching or entering the dentin

\section{Image C:}

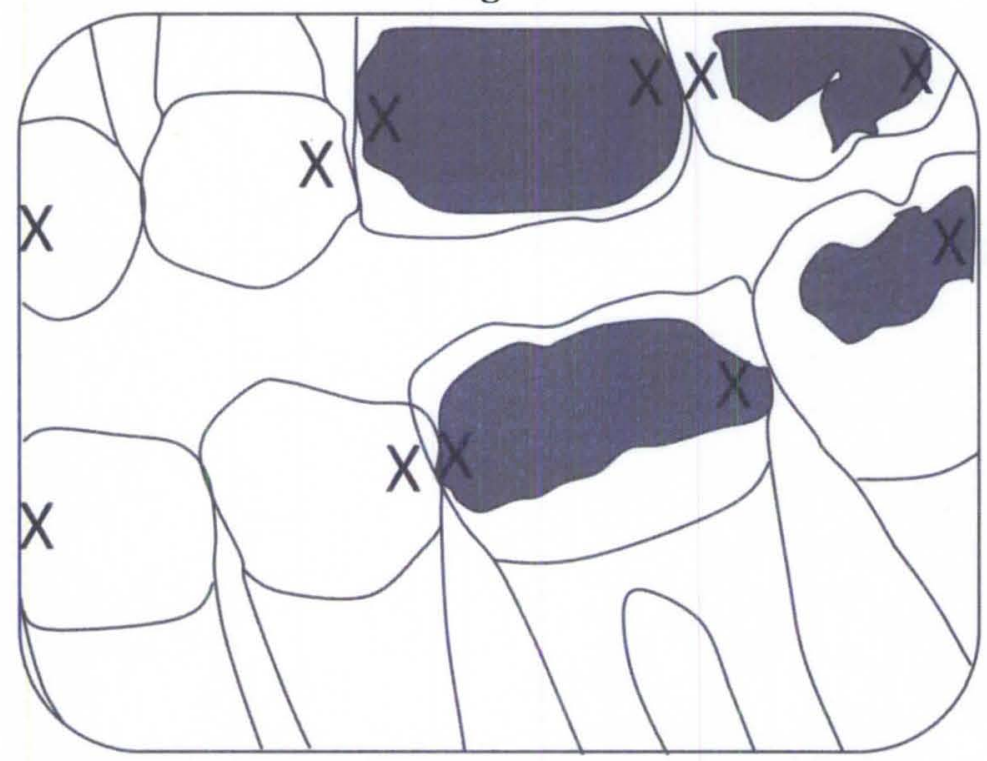

Image D:

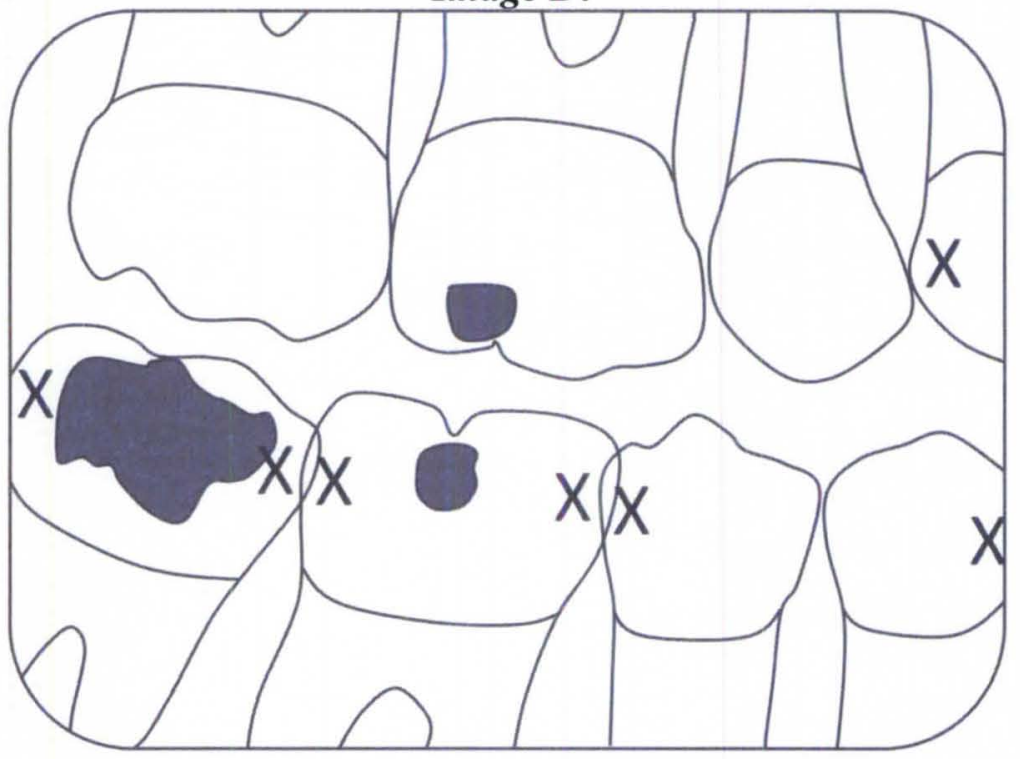




\section{OBSERVER ANSWER SHEET}

Observer name:

Viewing condition:

\section{Possible answers:}

$0=$ No caries present

$1=$ Caries less than halfway through the enamel

$2=$ Caries halfway or more through the enamel but not into the dentin

$3=$ Caries through the enamel and touching or entering the dentin
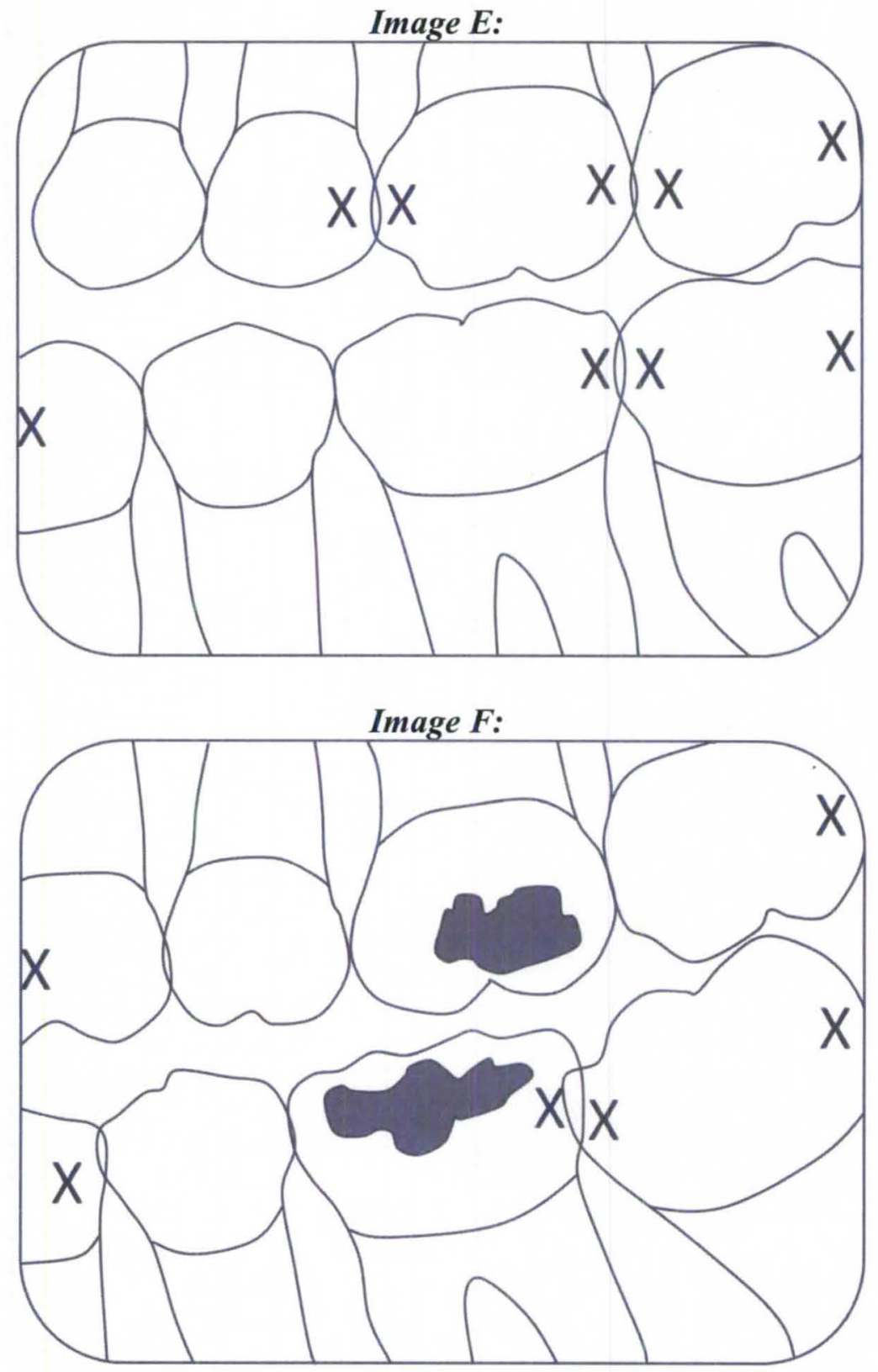


\section{OBSERVER ANSWER SHEET}

Observer name:

Viewing condition:

\section{Possible answers:}

$0=$ No caries present

$1=$ Caries less than halfway through the enamel

$2=$ Caries halfway or more through the enamel but not into the dentin

$3=$ Caries through the enamel and touching or entering the dentin
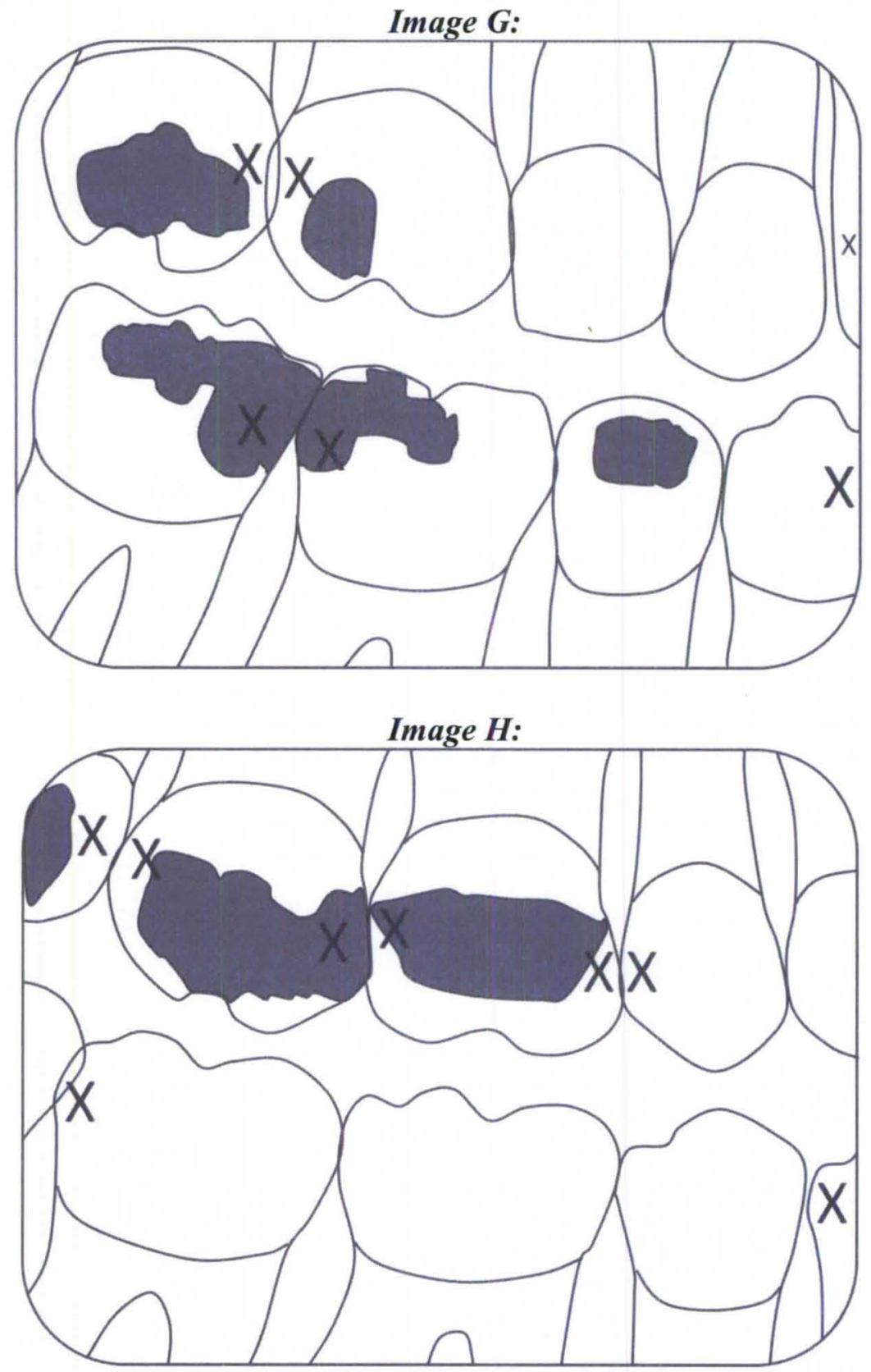


\section{OBSERVER ANSWER SHEET}

Observer name:

Viewing condition:

Possible answers:

$0=$ No caries present

$1=$ Caries less than halfway through the enamel

$2=$ Caries halfway or more through the enamel but not into the dentin

$3=$ Caries through the enamel and touching or entering the dentin

Image I:

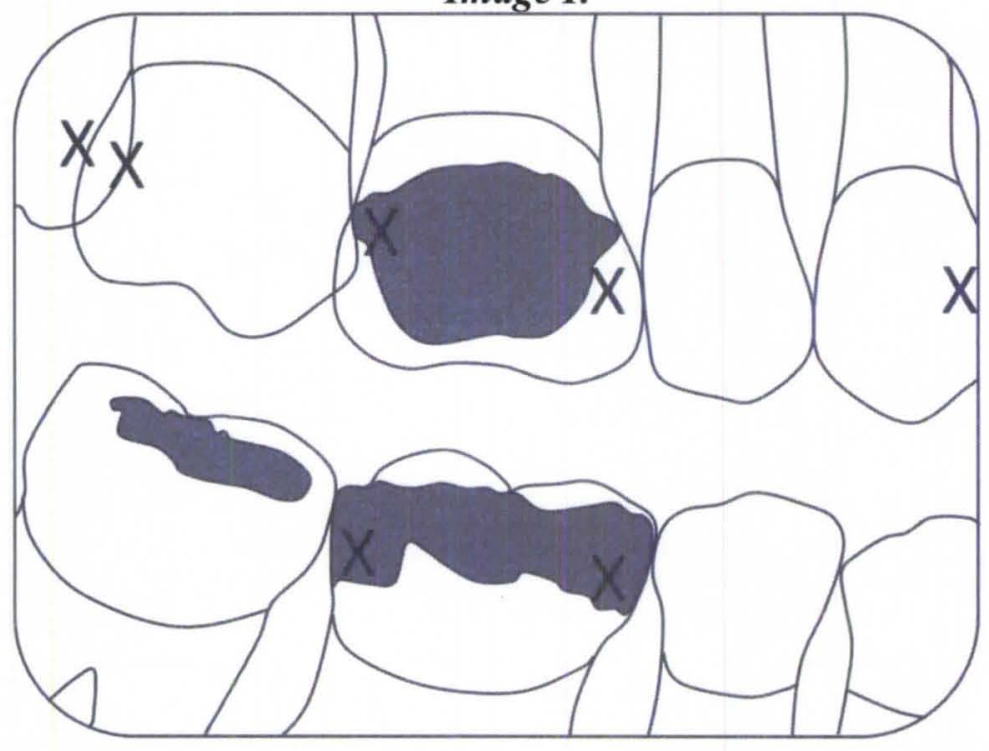

Image J:

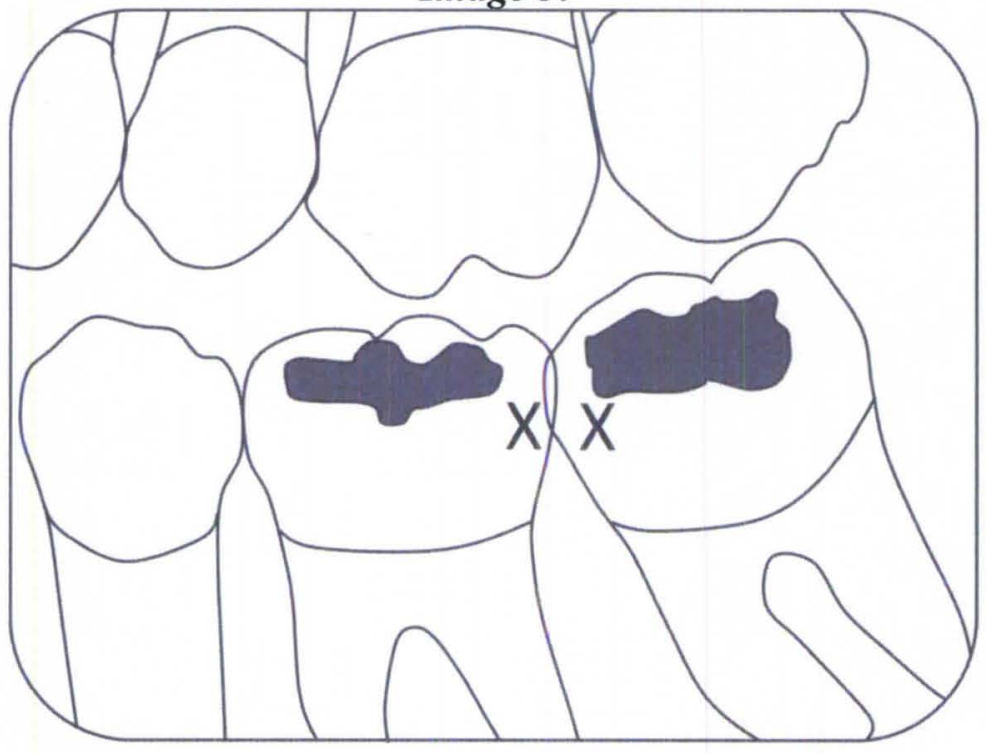




\section{OBSERVER ANSWER SHEET}

Observer name:

Viewing condition:

\section{Possible answers:}

$0=$ No caries present

$1=$ Caries less than halfway through the enamel

$2=$ Caries halfway or more through the enamel but not into the dentin

$3=$ Caries through the enamel and touching or entering the dentin
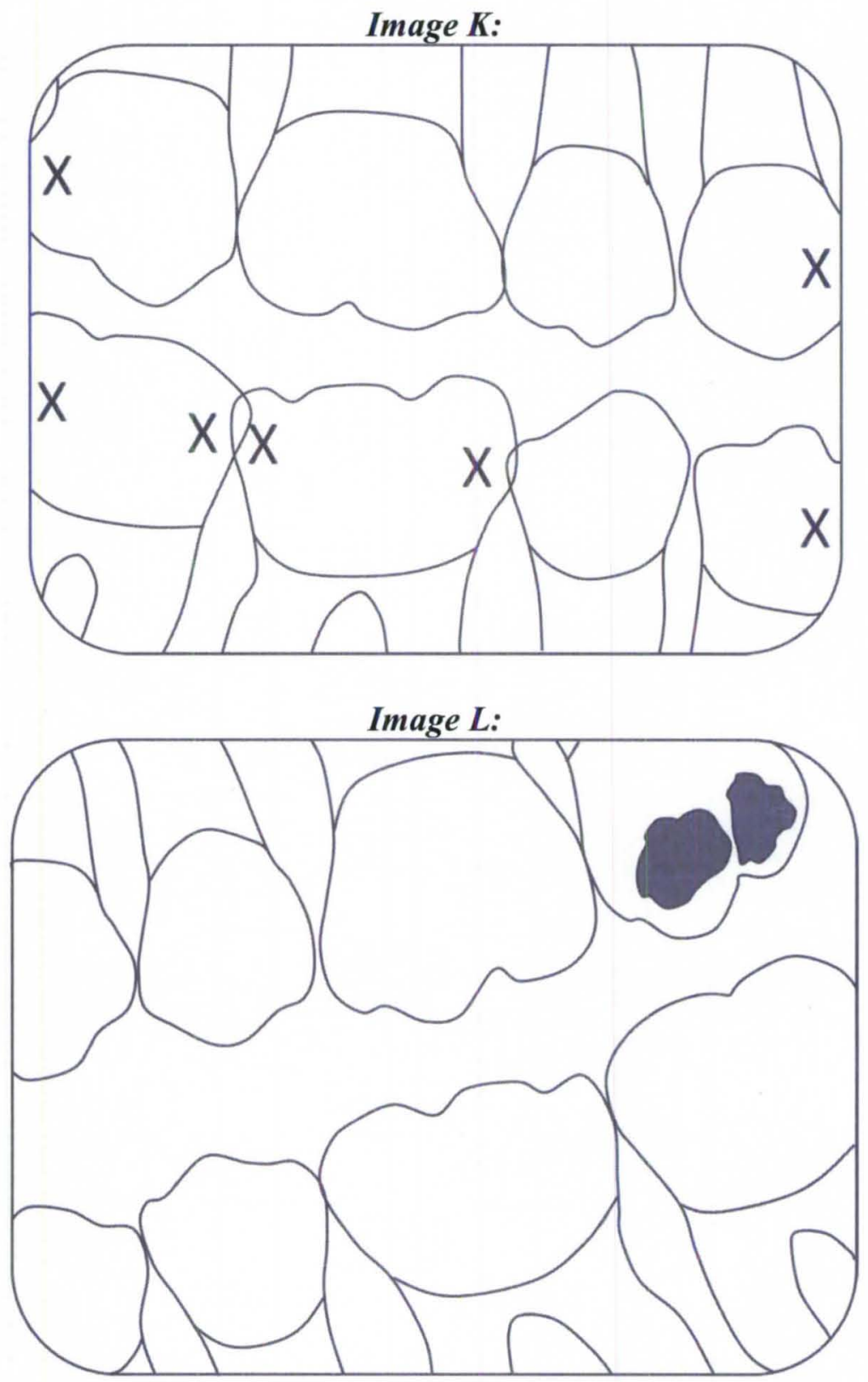


\section{OBSERVER ANSWER SHEET}

Observer name:

Viewing condition:

Possible answers:

$0=$ No caries present

$1=$ Caries less than halfway through the enamel

$2=$ Caries halfway or more through the enamel but not into the dentin

$3=$ Caries through the enamel and touching or entering the dentin

Image M:

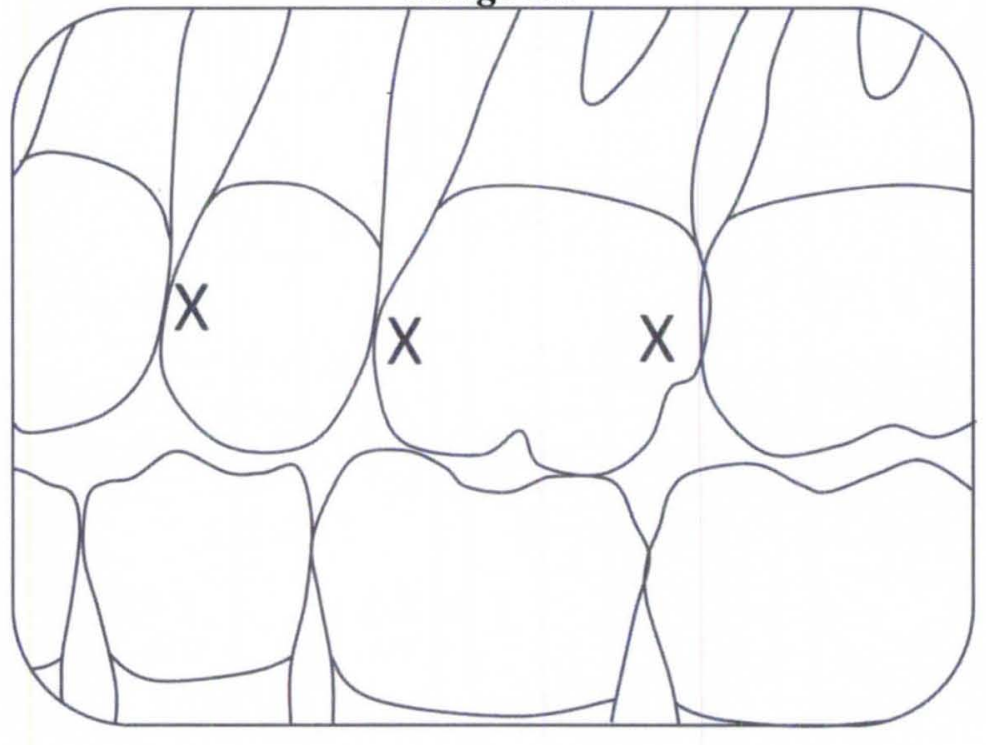

Image N:

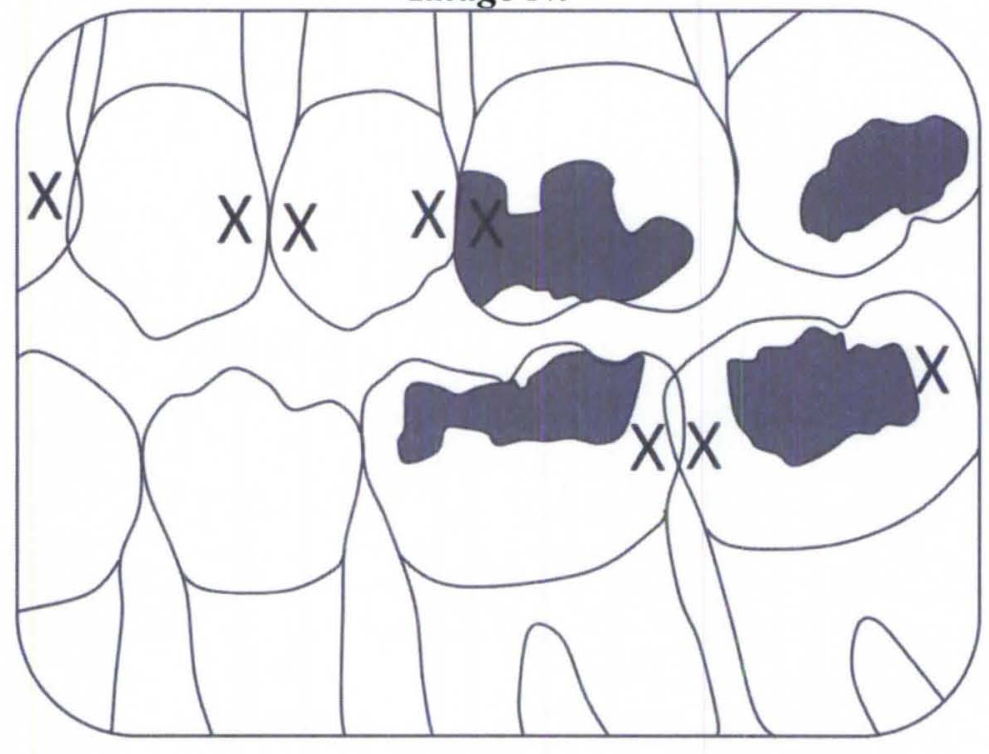




\section{OBSERVER ANSWER SHEET}

Observer name:

Viewing condition:

Possible answers:

$0=$ No caries present

$1=$ Caries less than halfway through the enamel

$2=$ Caries halfway or more through the enamel but not into the dentin

$3=$ Caries through the enamel and touching or entering the dentin
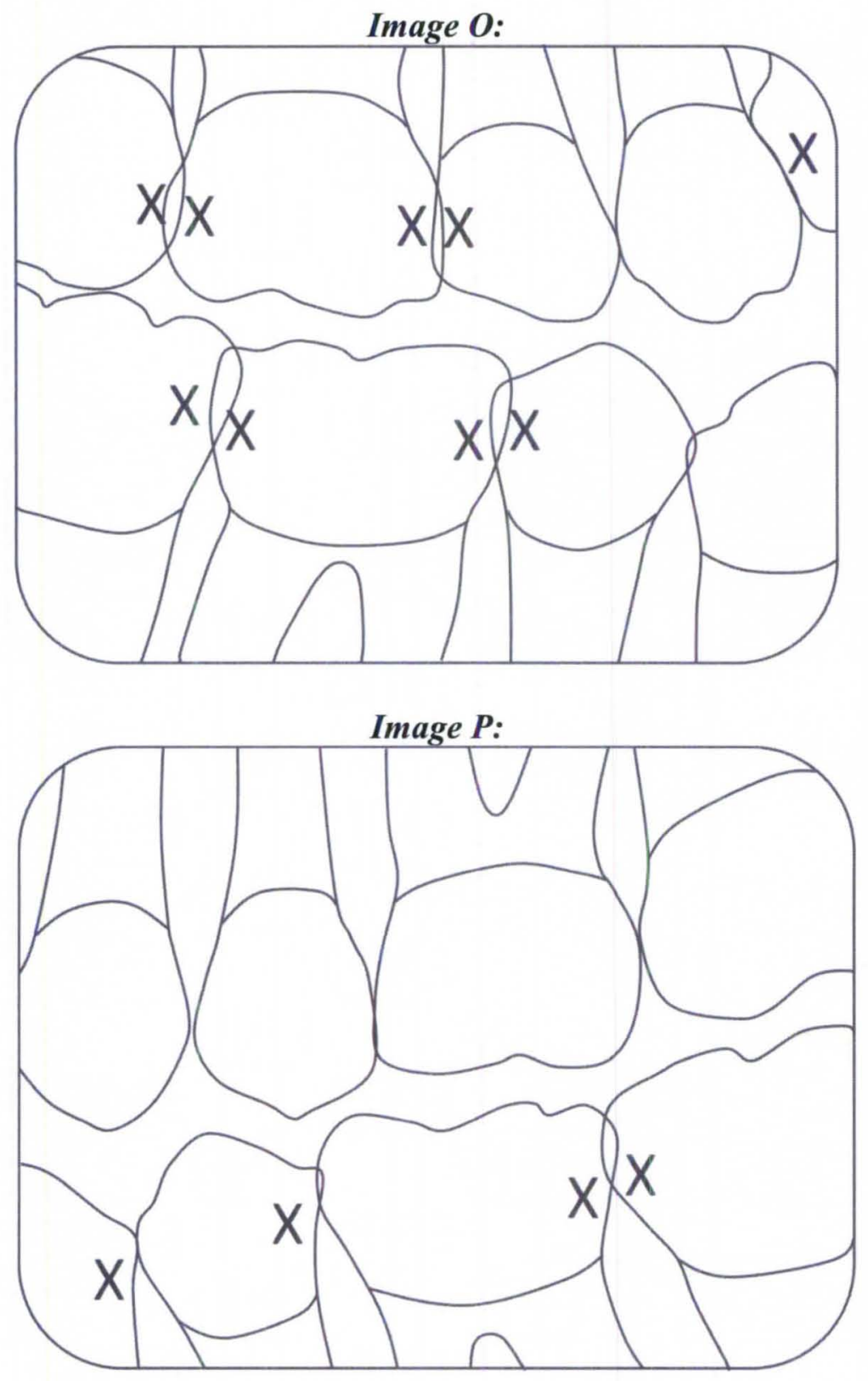


\section{OBSERVER ANSWER SHEET}

Observer name:

Viewing condition:

\section{Possible answers:}

$0=$ No caries present

$1=$ Caries less than halfway through the enamel

$2=$ Caries halfway or more through the enamel but not into the dentin

$3=$ Caries through the enamel and touching or entering the dentin

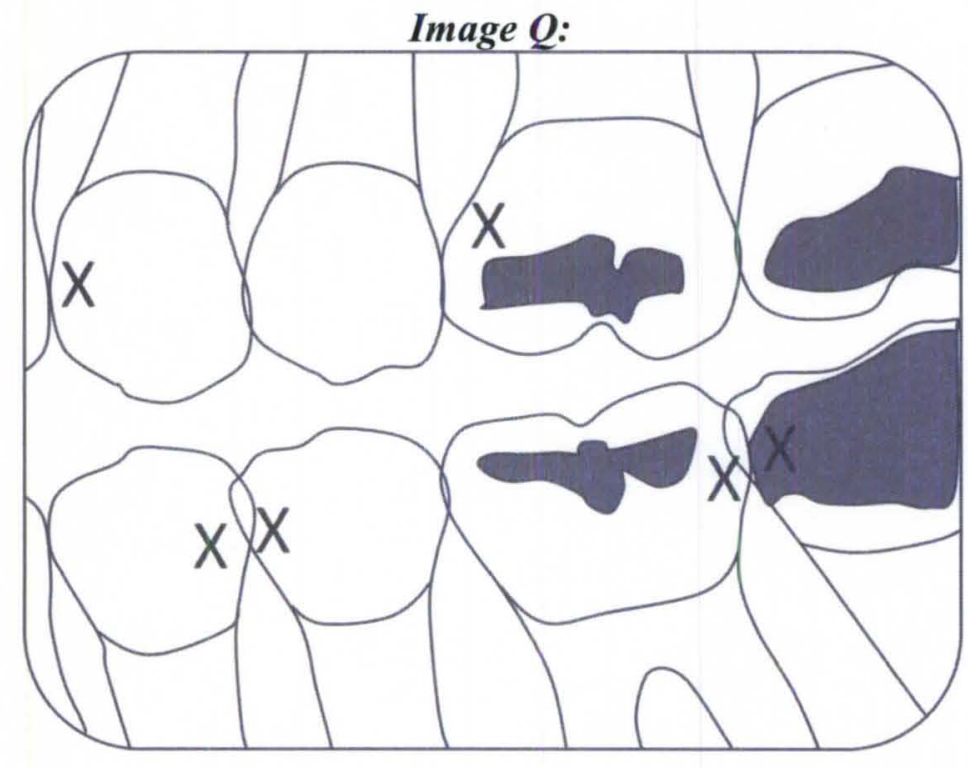

Image R:

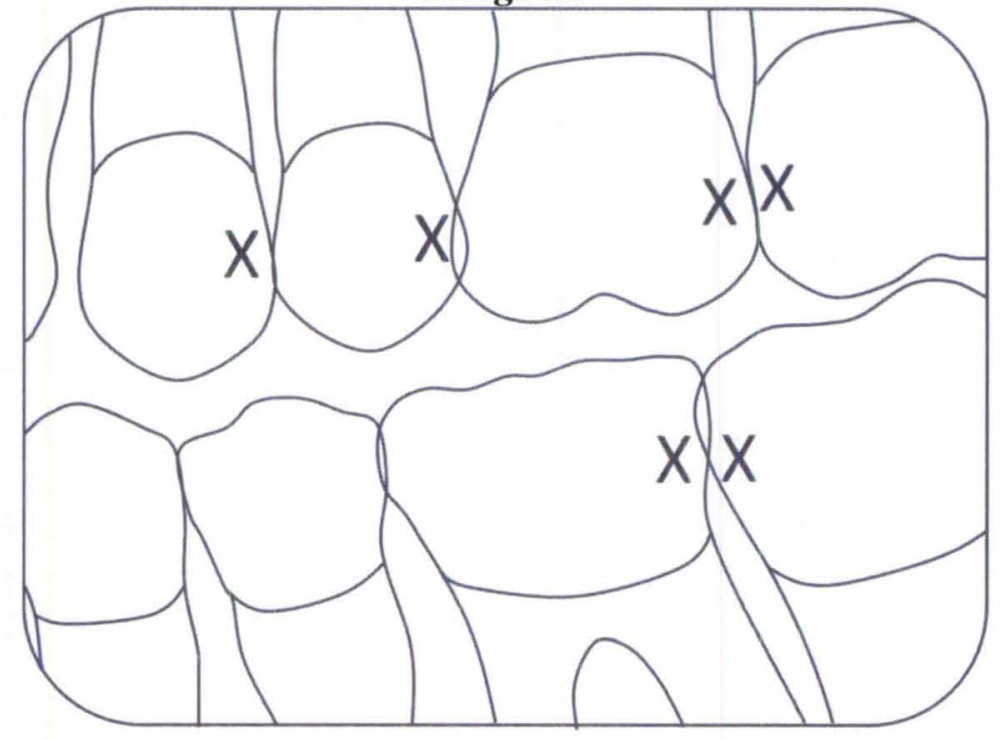




\section{CURRICULUM VITAE}

\section{Lauren Christine Szechy}

\section{PERSONAL INFORMATION}

Address:

1609 Stevens Ave

Louisville, KY 40205

Telephone:

(440) 503-5238

Email address:

szechylc@gmail.com

Birthplace/date:

Cleveland, OH, September, 7, 1989

\section{EDUCATION}

Bachelor of Science, University of Dayton, 2010

Double major: Pre-dentistry, Spanish

Minor: Biology

Dean's List

Presidents Scholarship recipient

Universidad Pablo de Olavide, Seville, Spain, 2009

\section{EXPERIENCE}

Dental Associate, 2012 - present

University of Louisville School of Dentistry

Simulation Clinic

Volunteer, $2007-2010$

Family \& Cosmetic Dentistry

Dr. Samuel Barther DDS 
Volunteer, $2003-2010$

Dr. Rochelle Friedrich DDS

Junior Ambassador, 2006

The Cleveland Clinic

\section{ACTIVITIES}

Operation Smile: Louisville Chapter

Co-founder

Public Relations \& Recruitment Chair

University of Dayton Dental Interest Group

\section{LANGUAGES}

Fluent in Spanish and English 